\title{
Large-scale flood risk assessment under different development strategies: the Luanhe River Basin in China
}

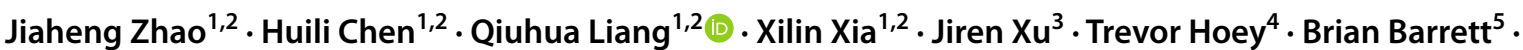 \\ Fabrice G. Renaud ${ }^{3} \cdot$ Lee Bosher $^{2} \cdot$ Xin Zhou $^{6}$
}

Received: 19 April 2021 / Accepted: 30 August 2021 / Published online: 11 October 2021

(c) The Author(s) 2021

\begin{abstract}
Increasing resilience to natural hazards and climate change is critical for achieving many Sustainable Development Goals (SDGs). In recent decades, China has experienced rapid economic development and became the second-largest economy in the world. This rapid economic expansion has led to large-scale changes in terrestrial (e.g., land use and land cover changes), aquatic (e.g., construction of reservoirs and artificial wetlands) and marine (e.g., land reclamation) environments across the country. Together with climate change, these changes may significantly influence flood risk and, in turn, compromise SDG achievements. The Luanhe River Basin (LRB) is one of the most afforested basins in North China and has undergone significant urbanisation and land use change since the 1950s. However, basin-wide flood risk assessment under different development scenarios has not been considered, although this is critically important to inform policy-making to manage the synergies and trade-offs between the SDGs and support long-term sustainable development. Using mainly open data, this paper introduces a new framework for systematically assessing flood risk under different social and economic development scenarios. A series of model simulations are performed to investigate the flood risk under different land use change scenarios projected to 2030 to reflect different development strategies. The results are systematically analysed and compared with the baseline simulation based on the current land use and climate conditions. Further investigations are also provided to consider the impact of climate change and the construction of dams and reservoirs. The results potentially provide important guidance to inform future development strategies to maximise the synergies and minimise the trade-offs between various SDGs in LRB.
\end{abstract}

Keywords Sustainable Development Goals $\cdot$ Flood risk $\cdot$ Climate change $\cdot$ Land use change $\cdot$ Hydrodynamic flood modelling · Open data

\section{Introduction}

To achieve a sustainable future, the UN's 2030 Agenda for Sustainable Development (UN 2015) proposed an ambitious plan of action for "People, planet, and prosperity".

Handled by Osamu Saito, Institute for Global Environmental The Agenda sets out 17 Sustainable Development Goals

Strategies, Japan.

Huili Chen

h.chen2@1boro.ac.uk

Qiuhua Liang

q.liang@lboro.ac.uk

1 Institute for Hydroinformatics and Hazard Resilience (IHHR), Hebei University of Engineering, Handan, China

2 School of Architecture, Building and Civil Engineering, Loughborough University, Loughborough, UK
3 School of Interdisciplinary Studies, University of Glasgow, Dumfries, UK

4 Department of Civil and Environmental Engineering, Brunel University London, London, UK

5 School of Geographical and Earth Sciences, University of Glasgow, Glasgow, UK

6 Institute for Global Environmental Strategies (IGES), Hayama, Japan 
(SDGs) adopted by all member states to action to end poverty, hunger and inequalities and protect the planet, ensuring all people enjoy peace and prosperity by 2030 . The Agenda recognises that disasters linked to natural hazards could set back development progress in some countries, especially in low- and middle-income countries (UN 2015). In this context, disaster risk reduction (DRR) is important to the Sustainable Development Agenda and is primarily driven by the Sendai Framework for Disaster Risk Reduction 2015-2030 (UNISDR 2015). DRR is directly or indirectly incorporated in the SDG framework, and its importance has been explicitly recognised in many targets, including building the resilience of the poor and reducing their exposure to climaterelated disasters (Target 1.5), ensuring sustainable and resilient food production systems that maintain ecosystems and adapt to climate change (Target 2.3), building sustainable and resilient infrastructure (Target 9.1), reducing deaths and impacts from disasters including water-related disasters (Target 11.5), implementing integrated policies for holistic DRR in link with the Sendai Framework (Target 11.b), and the targets under Goal 13 of climate action including particularly Target 13.1 on strengthening resilience and adaptive capacity to climate-related hazards and natural disasters and Target 13.3 on awareness-raising and capacity building on climate mitigation, adaptation and early warning. Achieving these Goals and Targets will impact further on the achievement of other SDGs, particularly SDG 1 (no poverty), SDG 3 (good health and well-being), SDG 5 (gender equality), SDG 6 (clean water and sanitation), SDG 8 (decent work and economic growth), SDG 10 (reducing inequalities) and SDG 15 (protection of ecosystems and biodiversity).

Flooding is one of the most widespread natural hazards globally, flood-related disasters accounting for $44 \%$ of the total number of globally recorded natural disasters between 2000 and $2019,41 \%$ of the total affected people, and $22 \%$ of the total economic losses, with China being one of the most affected countries (CRED and UNDRR 2020). Flood risk is increasing due to climate change and more active human-landscape interaction (IPCC 2014; Hirabayashi et al. 2013; Arnell and Gosling 2016). In particular, the impact of climate change on flood risk can be exacerbated by rapid and uncontrolled economic development that leads to increasing impermeable surface area; population growth and socio-economic development continue to drive rapid land use change and developments in flood-prone areas, potentially increasing flood exposure and eventually flood risk.

In the past few decades, substantial research has been undertaken to better understand the impact of climate change on flood risk from the global to local scales. For example, on the global scale, Hirabayashi et al. (2013) investigated flood risk in the 21 st century by applying a global river routing model under four different Representative Concentration Pathway (RCP) scenarios, revealing an increase in flood frequency in Southeast Asia, Peninsular India, eastern Africa and the northern Andes. On the continental or regional scale, Bevacqua et al. (2019) analysed the concurrence of high sea level and heavy precipitation events across Europe, showing that the Mediterranean coasts are currently subject to the highest probability of compound flooding, and parts of the northern European coast may expect a higher probability of compound flooding in the future due to climate change. At a national scale, Miller and Hutchins (2017) provided an overview of the flood risk in the UK under the impacts of urbanisation and climate change. At a more localised scale, Bouwer et al. (2010) combined projected future socio-economic change (land use change and increase in the value of assets), flood scenarios and a simple damage model to investigate the variation in future flood risk due to climate change and development in a Dutch polder area. Most of these studies, although at a range of scales, have concluded that climate change and human activity will change future flood risk and so will cause greater challenges in developing effective multi-scale flood risk management strategies to ensure flood resilience and sustainability.

The adaptive capacity to address flood risk on a local or regional scale is one of the most critical factors for timely and effective decision-making on developing strategies (Bosher and Chmutina 2017), which is especially germane in the context of dynamically changing socio-economic and climatic conditions. Scott et al. (2013) argue that any development in a flood-risk area that does not factor in flood risk reduction and management is not going to be sustainable in the long term. Likewise, Lizarralde et al. (2015) explain that, while there are challenges to making physical built assets more sustainable and suitably resilient to hazards such as floods, there are also exciting opportunities for synergy. Therefore, scientists and engineers are increasingly being urged to quantify flood risk under different scenarios so that more informed decisions can be made about how new developments can be planned, designed and constructed to be more resilient and sustainable for the long term.

Socio-economic development drives land use and land cover (LULC) changes, affecting hydrological processes that may lead to flooding and also determine water resources and the transport and dilution of pollutants (Wheater and Evans 2009). Based on LULC scenarios representing different socio-economic development strategies, Te Linde et al. (2011) estimated both current and future (2030) fluvial flood risk for the whole Rhine basin, summarised that a major part of annual expected damage in the Rhine basin was imposed by climate change. Whilst substantial research has been undertaken to understand and assess flood risk under different climate change and LULC conditions (e.g., Lugeri et al. 2010; Akter et al. 2018), most published studies have focused on high-income nations due to the availability of high-quality data and modelling and assessment tools. 
Furthermore, flood risk is directly impacted by climate change and socio-economic development, and so is inevitably an important factor to be considered when implementing the SDGs. Flood risk may significantly affect the linkages between the SDGs (Baldassarre et al. 2019). There are apparent research needs, including the development of fit-for-purpose flood risk assessment frameworks to better understand how flood risk is related to the synergies and trade-offs between the SDGs that are influenced by social development, human-environment interactions, and climate change. A particular focus should be placed on developing countries where further research is urgently needed to better understand the interconnected links between socio-economic development, climate change and flood risk, and provide scientific evidence to inform SDG implementation policies to minimise trade-offs and maximise synergies.

After 40 years of rapid economic development, China has become the second largest economy in the world but remains to be the largest developing economy with a per capita GDP of only $1 / 6^{\text {th }}$ that of the United States. China's rapid economic development has created noticeable impacts on the environment, climate and social elements which are inevitably linked to future flood risk and create different barriers in the realisation of SDGs at different levels. Being part of an important socio-economic zone in North-Eastern China, the Luanhe River Basin (LRB) has undergone rapid socio-economic development in the last 40 years that has been significantly influenced by Central and local government policies, leading to tremendous changes of land use, land cover and environment. It provides an ideal case study to investigate and understand the change of the flood risk influenced by different levels of policies and climate change and its linkages with SDG realisation at a basin level, which has not been done. Therefore, this study presents an integrated framework to systemically analyse flood risk under different socio-economic development strategies and climate change scenarios in LRB, providing essential information to better understand the interlinkages between different SDGs. Based on a high-performance hydrodynamic flood model and open data, the flood risk assessment framework can be applied to river basins in other developing countries where access to high-quality data is limited.

\section{Study area and datasets}

This work focuses on a river basin/catchment that provides a natural hydrological unit to support flood risk assessment and understand the impact of national and basin-level policies on local development and SDG achievement. Being home to a large population and 27 counties in Hebei Province, Inner Mongolia and Liaoning Province, the case study, LRB, is an important socio-economic zone on its own in North-Eastern China, and also directly contributes to and influences the socio-economic development of the BeijingTianjin-Hebei region.
Fig. 1 Location and terrain of LRB and the locations of precipitation stations and reservoirs

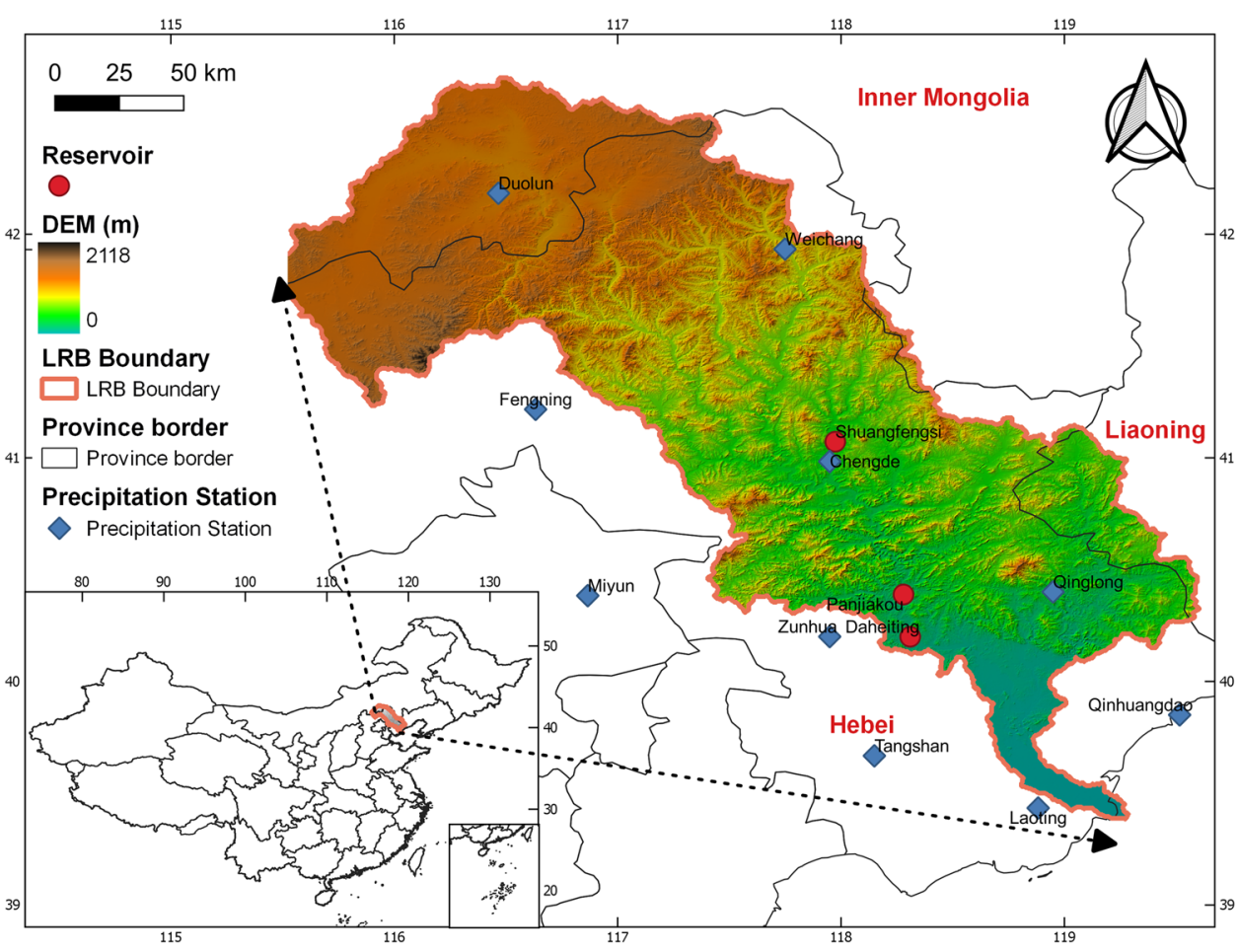




\section{Luanhe River Basin (LRB)}

The $44,750 \mathrm{~km}^{2}$ LRB is located in the northeast of the North China Plain $\left(115^{\circ} 30^{\prime} \mathrm{E}-119^{\circ} 45^{\prime} \mathrm{E}, 39^{\circ} 10^{\prime} \mathrm{N}-42^{\circ} 40^{\prime}\right.$ N) (Fig. 1). The $888 \mathrm{~km}$ long Luanhe River originates from Bayanguertu Mountain, Fengning County, Hebei province, flows through Hebei Province, Inner Mongolia and Liaoning Province, and finally enters Bohai Bay at Laoting County (Liu 2012). About $98.2 \%\left(43,940 \mathrm{~km}^{2}\right)$ of the river basin area is classified as mountainous landscapes with the dramatic change of elevation from north to south, before the basin enters a low elevation coastal plain at its southern end. The climate across the basin changes from semi-arid temperate continental monsoon to semi-humid, and finally to humid from northwest to southeast (Bi et al. 2018). According to the records between 1982 and 2015, the basin-wide mean annual temperature and precipitation are $7.0 \pm 2.6{ }^{\circ} \mathrm{C}$ and $488.4 \pm 80.7 \mathrm{~mm}$, respectively (Wu et al. 2020). The precipitation demonstrates a clear heterogeneous seasonal distribution with the main wet period in July and August every year (Sheng and Xiuling 2004; Lu 2005; Jiang et al. 2019). Overall, the basin has a complex climate pattern featured with four distinct seasons, significant monsoon effects, concentrated precipitation and heat over the same period.

LRB has a population of approximately 7.23 million, and the average density of population is 162 people $/ \mathrm{km}^{2}$. The GDP per capita is about $50 \%$ more than the national average (Liu 2012). The predominant land use types in the basin are forest, agriculture, grassland and urbanised areas ( $\mathrm{Li}$ et al. 2018). In particular, LRB provides an essential ecological barrier to alleviate the impact of sandstorms that originate in Mongolia on Beijing and the surrounding areas. With three large reservoirs, at Panjiakou, Daheiting and Shuangfengsi (under construction) (Fig. 1), the basin provides important water resources for the Beijing-Tianjin-Hebei region, which is the most socio-economically active region in North China (Wu et al. 2020), and thus the LRB directly contributes to the region's development.

As shown in Fig. 1, the LRB becomes significantly narrower in its furthest downstream reaches. This, combined with the upstream mountainous landscape, leads to rapidly converging flood flows during wet seasons, increasing flood risk in the downstream floodplain areas where major cities, including Qinhuangdao and Tangshan, are located (Shao et al. 2001). The basin's specific climate and landscape features make it vulnerable to large flood events (Han 1999; Yang and Yang 2013). Therefore, LRB provides an ideal case study to investigate the linkages between rapid economic development, key infrastructure construction (dams and reservoirs), environmental protection (afforestation to mitigate sandstorm impacts), flood risk and climate change. Particularly, the rapid land use change as a result of accelerating economic development has created significant impacts on hydrological processes, which, combined with climate changes, may significantly change flood risk across the basin. However, whilst it can provide essential information to support policy-making and planning for LRB's sustainable future, basin-wide flood risk assessment under different development strategies has not been conducted so far.

\section{Data}

The proposed flood risk assessment framework (see "The flood risk assessment framework") adopts a high-performance hydrodynamic model to predict flood inundation, which requires spatial data, including a digital elevation model (DEM) and land use maps covering the whole domain for model set-up. Three sets of rainfall data are used to drive flood simulations, including historical rainfall records from the surrounding meteorological stations for reproducing a historical flood event for model calibration, city-wise design rainfall to drive the simulation of flood scenarios and different Representative Concentration Pathway (RCP) data to account for the impact of future climate change. Climate projections were extracted from the NASA Earth Exchange Global Daily Downscaled Projections (NEX-GDDP) dataset, which provides downscaled climate scenarios across the globe, derived from the simulation results from 21 General Circulation Models (GCMs) through the Coupled Model Intercomparison Project Phase 5 (CMIP5) for both RCP4.5 and RCP8.5 (Thrasher and Nemani 2015). Each of the climate projections includes daily maximum temperature, minimum temperature, and precipitation for the period between 1950 and 2100, wherein precipitation from 1950 to 2005 is defined as the 'retrospective run' and from 2006 to 2099 as the 'prospective run'. Furthermore, open remote sensing data are available to provide observed flood extent for validating model results. The Gridded Population of the WorldVersion 4 (GPWv4) is further used to assess the population at risk. The key datasets used in this study are summarised in Table 1. The current risk assessment framework mainly uses open data to ensure the transferability of the approach to other river basins, especially those in developing countries where data availability may be limited.

\section{The flood risk assessment framework}

In the flood risk assessment framework developed herein for LRB, city-wise design rainfall is first derived to drive flood inundation modelling using the High-Performance Integrated hydrodynamic Modelling System (HiPIMS) (Liang and Smith 2015; Xia et al. 2019). The flood modelling results are then combined with the land use and population data to evaluate flood impact and indicate flood risk. The different components/procedures considered in the 
Table 1 The datasets used by the flood risk assessment framework, and their sources

\begin{tabular}{|c|c|c|}
\hline Data type & Scale/resolution & Data source \\
\hline \multicolumn{3}{|l|}{ Spatial data } \\
\hline DEM & $90 \mathrm{~m} \times 90 \mathrm{~m}$ & MERIT Hydro: (http://hydro.iis.u-tokyo.ac.jp/ yamadai/MERIT_Hydro/) \\
\hline Land use data & $90 \mathrm{~m} \times 90 \mathrm{~m}$ & $\begin{array}{l}\text { Resources and Environmental Sciences Data Centre, Chinese Academy of Sciences (http://www.resdc. } \\
\mathrm{cn} / \text { ) }\end{array}$ \\
\hline \multicolumn{3}{|l|}{ Meteorologic data } \\
\hline Daily rainfall & 10 stations & China Meteorological Data Service Centre (http://data.cma.cn) \\
\hline Design rainfall & 8 cities & Hydrological Yearbook \\
\hline RCPs & $0.25^{\circ} \times 0.25^{\circ}$ & $\begin{array}{l}\text { NASA Earth Exchange Global Daily Downscaled Projections (https://www.nccs.nasa.gov/services/data- } \\
\text { collections/land-based-products/nex-gddp) }\end{array}$ \\
\hline \multicolumn{3}{|l|}{ Remote sensing } \\
\hline Landsat 7 & $30 \mathrm{~m} \times 30 \mathrm{~m}$ & $\begin{array}{l}\text { Landsat } 7 \text { top-of-atmosphere (TOA) reflectance image collections available from Google Earth Engine } \\
\text { (http://earthengine.google.org), collected originally by USGS/EROS (http://landsat.usgs.gov/) }\end{array}$ \\
\hline MODIS & $250 \mathrm{~m} \times 250 \mathrm{~m}$ & $\begin{array}{l}\text { 16-day MOD13Q1 version } 6 \text { Terra Vegetation Indices product available from Google Earth Engine } \\
\text { (http://earthengine.google.org), collected originally by the NASA Earth Observing System (EOS) } \\
\text { (ftp://ladsweb.nascom.nasa.gov/allData/6/) }\end{array}$ \\
\hline \multicolumn{3}{|l|}{ Population } \\
\hline GPWv4 & $1000 \mathrm{~m} \times 1000 \mathrm{~m}$ & $\begin{array}{l}\text { Centre for International Earth Science Information Network-CIESIN_Columbia University. } 2018 . \\
\text { Gridded Population of the World, Version } 4 \text { (GPWv4): Population Density, Revision 11. Palisades, } \\
\text { NY: NASA Socio-economic Data and Applications Center (SEDAC) ( https://doi.org/10.7927/H49C6 } \\
\text { VHW) }\end{array}$ \\
\hline
\end{tabular}

flood impact/risk assessment are introduced in the following sections.

\section{Design rainfall and climate change impact}

The Chicago design storm model (Keifer and Chu 1957) is used to obtain the intensity-duration-frequency (IDF) curves for different administrative zones (i.e., cities) in LRB. The average rainfall intensity of a certain frequency (return period) can be defined as:

$i=\frac{A(1+C \lg P)}{(D+b)^{u}}$

where $i$ is the average rainfall intensity ( $\mathrm{mm} / \mathrm{min}), D$ is the storm duration (minutes); $P$ is the return period (years; only 100-year events are considered in this work and so $P=100$ years); $A, C, b$ and $u$ are model parameters representing local hydrological conditions, which are usually assumed to be constant and estimated by fitting the historical data (Keifer and Chu 1957). Herein, $D=24 \times 60 \mathrm{~min}$, i.e. 1-day event, is considered to maintain consistency with the daily climate data and a similar approach has been adopted by other researchers (e.g. Xu et al. 2012; Gilroy and McCuen 2012; Schuster et al. 2012; Chang et al. 2013).

From Eq. (1), a storm advancement coefficient $r=0.4$ (i.e. the ratio between the time to peak and rainfall duration) is further defined, based on which the rainfall distribution/ hyetograph can be calculated as follows:
Table 2 Parameters for deriving city-wise design storms in LRB

\begin{tabular}{lllll}
\hline City & $A_{1}$ & $C$ & $b$ & $u$ \\
\hline Tangshan & 11.90 & 0.69 & 10.23 & 0.702 \\
Zhangjiakou & 22.66 & 0.906 & 15.479 & 0.948 \\
Chengde & 17.747 & 0.789 & 14.72 & 0.829 \\
Chaoyang & 24.50 & 0.979 & 18.92 & 0.92 \\
Qinhuangdao & 3.6335 & 0.711 & 1.04 & 0.464 \\
Huludao & 13.20 & 0.85 & 7 & 0.8 \\
Chifeng & 9.60 & 1.35 & 10 & 0.8 \\
Xilinguole & 6.76 & 1.55 & 12.77 & 0.715 \\
\hline
\end{tabular}

$i(t)=\frac{A(1+C \lg P)\left[(1-u) t / R_{t}+b\right]}{\left(t / R_{t}+b\right)^{u+1}}$

with $R_{t}=r$ for $t<D_{p}$, and $R_{t}=1-r$ for $t \geq D_{p}$, where $D_{p}$ is the time to peak. For different cities in the LRB, the relevant parameters of the above Chicago design storm model are obtained from the Chinese Hydrological Yearbook and summarised in Table 2.

To consider the potential climate change impact on rainfall and thus flood risk, the climate change scenarios RCP4.5 and RCP8.5 (IPCC 2014) are used. The uplift factors derived from the climate change modelling results are added to the city-wise IDF curves to account for the change to rainfall induced by climate change in 2030 . To obtain the uplift factors, a Log-Pearson type III distribution (Chow 1988) was fitted to the NEX-GDDP dataset to calculate the 
magnitudes of 100-year design rainfall at each pixel within the domain for the 'retrospective run' (i.e. the historical period between 1950 and 2005) without climate change to give $R_{\text {his }}$ (mm/day), and future periods (2006-2030) with climate change (RCP4.5 and RCP8.5) to provide $R_{\mathrm{cli}}(\mathrm{mm} /$ day). The pixel-based climate change uplift can then be calculated as $\operatorname{up}_{2006,2030}=R_{\mathrm{cli}} / R_{\text {his }}$. However, the baseline year for the land use analysis is 2015 , so the uplift values are adjusted accordingly to be consistent with the land use change scenarios. Assuming the impact of climate change on the design rainfall distributes linearly against time, the uplift factors calculated from 2015 are obtained via linear interpolation, up $_{2015,2030}=8$ up $_{2006,2030} /\left(3\right.$ up $\left._{2006,2030}+5\right)$, and the final results are presented in Fig. 2. The pixel-based uplift factors $\left(\mathrm{up}_{2015,2030}\right)$ are then resampled to $90 \mathrm{~m}$ resolution to be consistent with the DEM and land use data, and are further averaged to create the city-wise uplifts (right panel of Fig. 2, with the city boundaries illustrated in the central panel). These uplift factors are then applied to the design rainfall to account for climate change impact. The design rainfall (uniformly distributed across each of the pixels), with and without considering climate uplifts, will be used to drive flood modelling.

\section{Future land use and flood scenarios}

The design rainfall is combined with the future land use distributions to create flood scenarios to support further flood impact/risk analysis. Four future land use scenarios, labelled as "Trend", "Expansion", "Sustainability" and "Conservation", were designed and projected to 2030 by Xu et al. (2021) using the CLUMondo model (Asselen and Verburg 2013) to reflect different socio-economic development and environmental protection strategies, local development plans and policies (Fig. 3 and Table 3). The "Trend" scenario is projected as a pathway to maintain "business as usual", i.e., to follow the current development trend. The "Expansion" scenario follows the fossil-fuelled development or shared socio-economic pathway (SSP5) (O'Neill et al. 2014), in which abundant fossil fuel resources are exploited, the global economy grows at the highest speed, and the global urban population reaches $92 \%$ in 2100 . The "Sustainability" scenario is based on the sustainable shared socio-economic pathway (SSP1) (O'Neill et al. 2014). Finally, the "Conservation" scenario adopts the socio-economic context of the "Sustainability" scenario as a baseline, but it is extended by further implementing ecological restoration and environmental protection policies in the LRB.

The original 100-year design rainfall (without considering climate change impact) and the two sets of uplifted

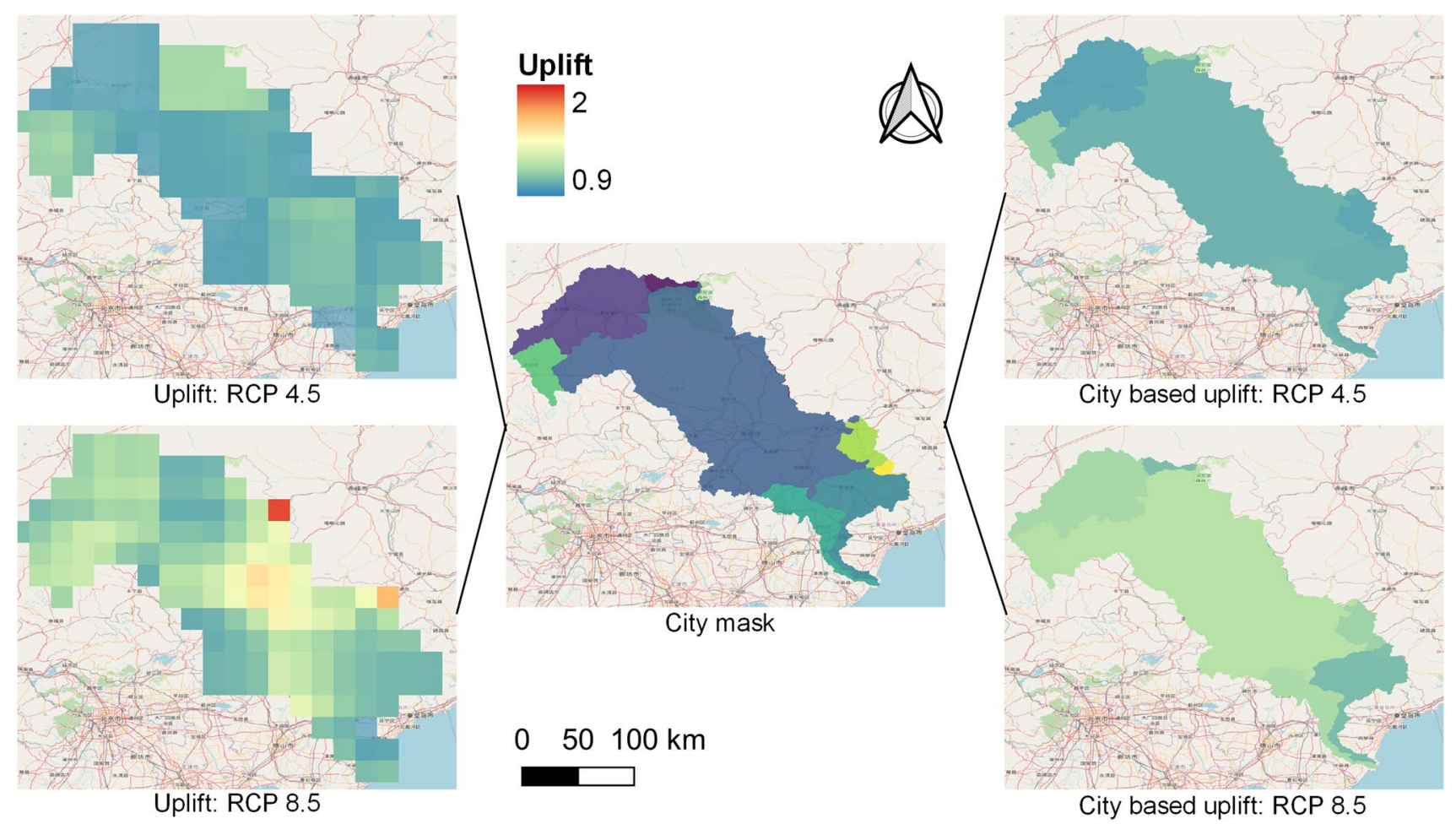

Fig. 2 City-wise climate uplift: pixel-based uplift data, with the pixel uplift value range from 0.9 to 2.0 (left panel); city mask specifying the city boundaries for uplift estimation (centre panel); and city-wise uplift factors (right panel) 

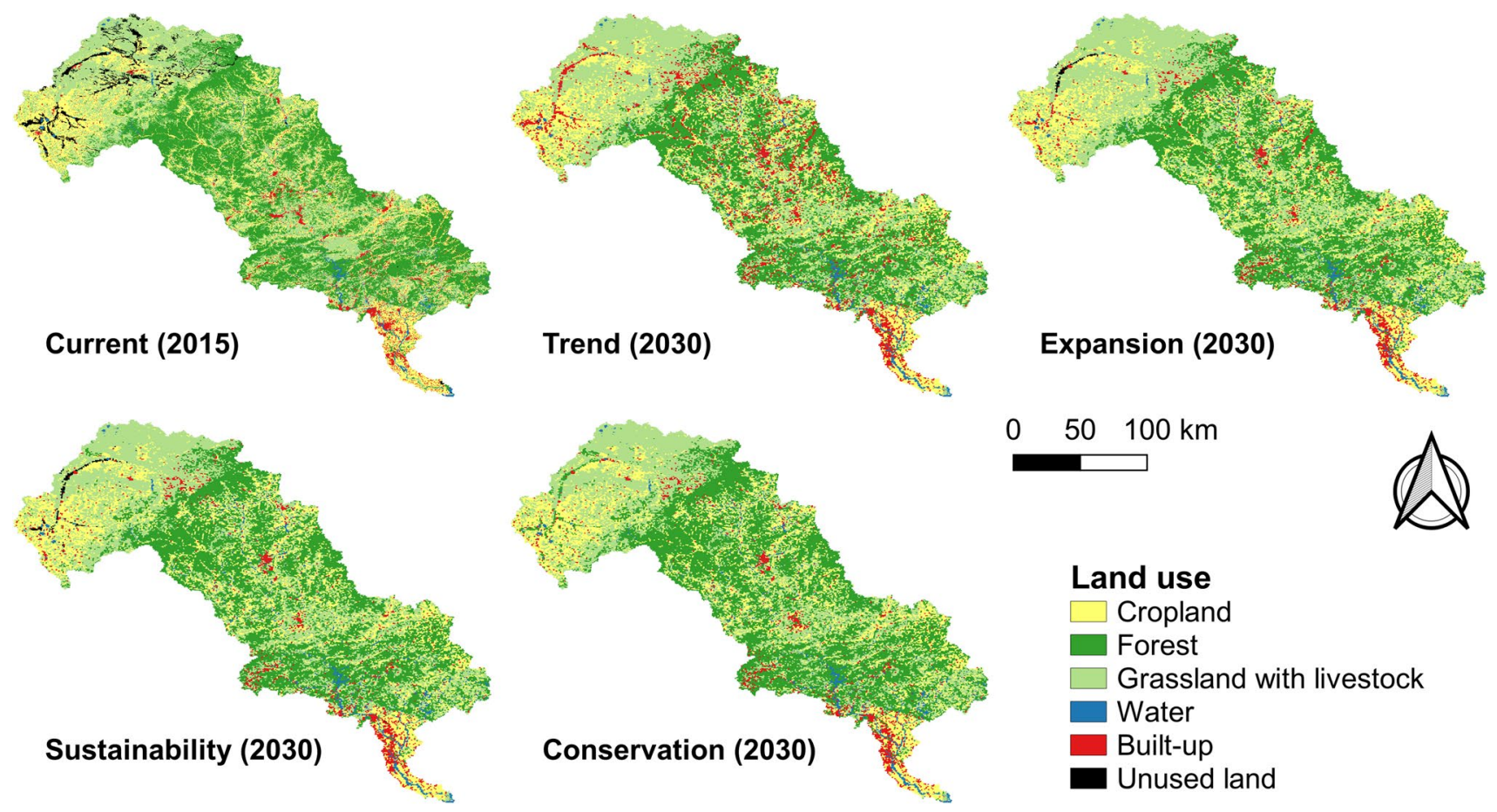

Fig. 3 The land use distributions of LRB at the current stage and under different socio-economic development strategies

Table 3 The areas $\left(\mathrm{km}^{2}\right)$ of different land use types: comparing the four future land use scenarios with the 'Baseline' condition in 2015

\begin{tabular}{|c|c|c|c|c|c|c|}
\hline Land use type & Cropland & Forest & $\begin{array}{l}\text { Grassland with } \\
\text { livestock }\end{array}$ & Water & Built-up & Unused land \\
\hline \multicolumn{7}{|c|}{ Socio-economic scenarios } \\
\hline Baseline & 10,258 & 16,926 & 14,101 & 718 & 1633 & 1114 \\
\hline Trend & 10,351 & 13,957 & 15,629 & 1003 & 3803 & 7.1 \\
\hline Expansion & 10,352 & 14,723 & 16,649 & 965 & 1977 & 84 \\
\hline Sustainability & 10,360 & 16,112 & 15,327 & 1093 & 1684 & 175 \\
\hline Conservation & 10,314 & 17,631 & 14,091 & 1033 & 1678 & 1.9 \\
\hline
\end{tabular}

design rainfall (considering RCP4.5 and RCP8.5 climate scenarios) are combined with the four projected land use patterns to create 12 flood scenarios. Taking two large reservoirs, Panjiakou and Shuangfengsi Reservoirs, as examples, further flood scenarios are designed to investigate the impact of this key type of infrastructure on flood risk. Since the Shuangfengsi Reservoir is currently under construction, it is not included in the original 12 flood scenarios. Considering, respectively, removing the Panjiakou Reservoir from and adding the Shuangfengsi Reservoir to the simulations, another 16 flood scenarios are created. Together with the 2015 Baseline simulation, it gives a total of 29 flood scenarios, as summarised in Table 4, which are simulated using HiPIMS in this work.

\section{Flood modelling}

To predict the rainfall-induced flooding process and the resulting inundation, the hydrodynamic flood model HiPIMS (Xia et al. 2019) is used in this work, which solves the shallow water equations (SWEs) written in matrix form as

$\frac{\partial \boldsymbol{q}}{\partial t}+\frac{\partial \boldsymbol{f}}{\partial x}+\frac{\partial g}{\partial y}=S$

where $t$ is time; $x$ and $y$ are the two spatial Cartesian coordinates; $\boldsymbol{q}$ is the vector of conserved flow variables; $\boldsymbol{f}$ and $\boldsymbol{g}$ are the vectors of fluxes in the $x$ - and $y$-directions, respectively; $\mathbf{S}$ contains different source/sink terms. The vector terms are given by: 
Table 4 The 29 flood scenarios designed to support flood risk analysis

\begin{tabular}{|c|c|c|c|}
\hline Rainfall & 100 -year design rainfall & $\begin{array}{l}\text { 100-year design rainfall (RCP4.5) 100- } \\
\text { year design rainfall (RCP4.5) }\end{array}$ & 100-year design rainfall (RCP8.5) \\
\hline \multicolumn{4}{|l|}{ Land use } \\
\hline Land use (2015) & Baseline & & \\
\hline Trend (2030) & Trend & $\begin{array}{l}\text { Trend (RCP4.5) } \\
\text { Trend (RCP4.5) }-\mathrm{P} \\
\text { Trend (RCP4.5) +S }\end{array}$ & $\begin{array}{l}\text { Trend (RCP8.5) } \\
\text { Trend (RCP8.5) - P } \\
\text { Trend (RCP8.5) +S }\end{array}$ \\
\hline Expansion (2030) & Expansion & $\begin{array}{l}\text { Expansion (RCP4.5) } \\
\text { Expansion (RCP4.5) - P } \\
\text { Expansion (RCP4.5) }+\mathrm{S}\end{array}$ & $\begin{array}{l}\text { Expansion }(\mathrm{RCP} 8.5) \\
\text { Expansion }(\mathrm{RCP} 8.5)-\mathrm{P} \\
\text { Expansion }(\mathrm{RCP} 8.5)+\mathrm{S}\end{array}$ \\
\hline Sustainability (2030) & Sustainability & $\begin{array}{l}\text { Sustainability }(\mathrm{RCP} 4.5) \\
\text { Sustainability }(\mathrm{RCP} 4.5)-\mathrm{P} \\
\text { Sustainability }(\mathrm{RCP} 4.5)+\mathrm{S}\end{array}$ & $\begin{array}{l}\text { Sustainability (RCP8.5) } \\
\text { Sustainability (RCP8.5) - P } \\
\text { Sustainability }(\mathrm{RCP} 8.5)+\mathrm{S}\end{array}$ \\
\hline Conservation (2030) & Conservation & $\begin{array}{l}\text { Conservation (RCP4.5) } \\
\text { Conservation }(\mathrm{RCP} 4.5)-\mathrm{P} \\
\text { Conservation }(\mathrm{RCP} 4.5)+\mathrm{S}\end{array}$ & $\begin{array}{l}\text { Conservation (RCP8.5) } \\
\text { Conservation }(\mathrm{RCP} 8.5)-\mathrm{P} \\
\text { Conservation }(\mathrm{RCP} 8.5)+\mathrm{S}\end{array}$ \\
\hline
\end{tabular}

Herein, 'P' represents Panjiakou Reservoir (including Daheiting); 'S' denotes Shuangfengsi Reservoir; '+ ' and '-'means adding and removing the respective reservoirs

$\boldsymbol{q}=\left[\begin{array}{l}h \\ q_{x} \\ q_{y}\end{array}\right], \boldsymbol{f}=\left[\begin{array}{c}q_{x} \\ q_{x}^{2} / h+g h^{2} / 2 \\ q_{x} q_{y} / h\end{array}\right], \boldsymbol{g}=\left[\begin{array}{c}q_{y} \\ q_{x} q_{y} / h \\ q_{y}^{2} / h+g h^{2} / 2\end{array}\right]$,
$\boldsymbol{S}=\boldsymbol{R}+\boldsymbol{S}_{b}+\boldsymbol{S}_{f}=\left[\begin{array}{c}R-I \\ 0 \\ 0\end{array}\right]+\left[\begin{array}{c}0 \\ -g h \partial z / \partial x \\ -g h \partial z / \partial y\end{array}\right]+\left[\begin{array}{c}0 \\ -C_{f} q_{x} \sqrt{q_{x}^{2}+q_{y}^{2}} / h^{2} \\ -C_{f} q_{y} \sqrt{q_{x}^{2}+q_{y}^{2}} / h^{2}\end{array}\right]$

in which $h$ is the water depth; $q_{x}=u h$ and $q_{y}=v h$ are the unit-width discharges in the $x$ - and $y$-directions, with $u$ and $v$ being the corresponding depth-averaged velocity components; $g=9.81 \mathrm{~m} / \mathrm{s}^{2}$ is the acceleration due to gravity. The source terms $\mathbf{S}$ are subdivided into the mass source terms $\boldsymbol{R}$ including rainfall rate $(R)$ and infiltration rate $(I)$, the slope source terms $S_{b}$ and the friction source terms $\boldsymbol{S}_{\boldsymbol{f}}$ to account for the effects of gravity and friction, respectively. Wherein, $z$ is the bed elevation extracted from the DEM data; $C_{f}=g$ $n^{2} / h^{1 / 3}$ is the friction parameter with $n$ being the Manning coefficient that can be assigned according to different land use types. The infiltration rate $I$ is estimated using the Green-Ampt method (Heber Green and Ampt 1911), which may be written as

$I=-\frac{d f}{d t}=-K_{s}\left[(\psi+h) \frac{\theta_{e}-\theta_{i e}}{f}+1\right]$

where $K_{s}$ is the hydraulic conductivity $(\mathrm{m} / \mathrm{s}) ; \psi$ is the capillary head (m); $\theta_{e}=\theta_{s}-\theta_{r}$ and $\theta_{i e}=\theta_{i}-\theta_{r}$ are respectively the effective porosity and initial effective soil moisture, with $\theta_{s}, \theta_{i}$ and $\theta_{r}$ defined as the saturated water content, initial water content and residual water content; $f$ is the cumulative infiltrated depth. The parameters $K_{s}, \psi, \theta_{e}$ and $\theta_{i e}$ are assumed to be constants throughout a simulation. Equation (5) may be solved using a backward Euler method to estimate the infiltration rate, as introduced in Xia et al. (2019).

In HiPIMS, the above governing SWEs are solved using a Godunov-type finite volume method implemented with the latest flux and source term discretisation schemes introduced by Zhao and Liang (2021) for stable and accurate prediction of overland flows and flooding processes. HiPIMS is implemented on multiple GPUs to achieve high-performance computing and has been widely applied and tested for the simulation of different types of flooding processes (e.g., Xia et al. 2019; Xing et al. 2019). During the simulations, the resolution of the computational grid is taken to be the same as the DEM data, and the time step is controlled by the CFL condition. In this work, HiPIMS will be calibrated for application in LRB by reproducing a historical flood event. 
Fig. 4 Rainfall records during the 2012 Typhoon Saola and Damrey from Meteorological Monitoring Stations

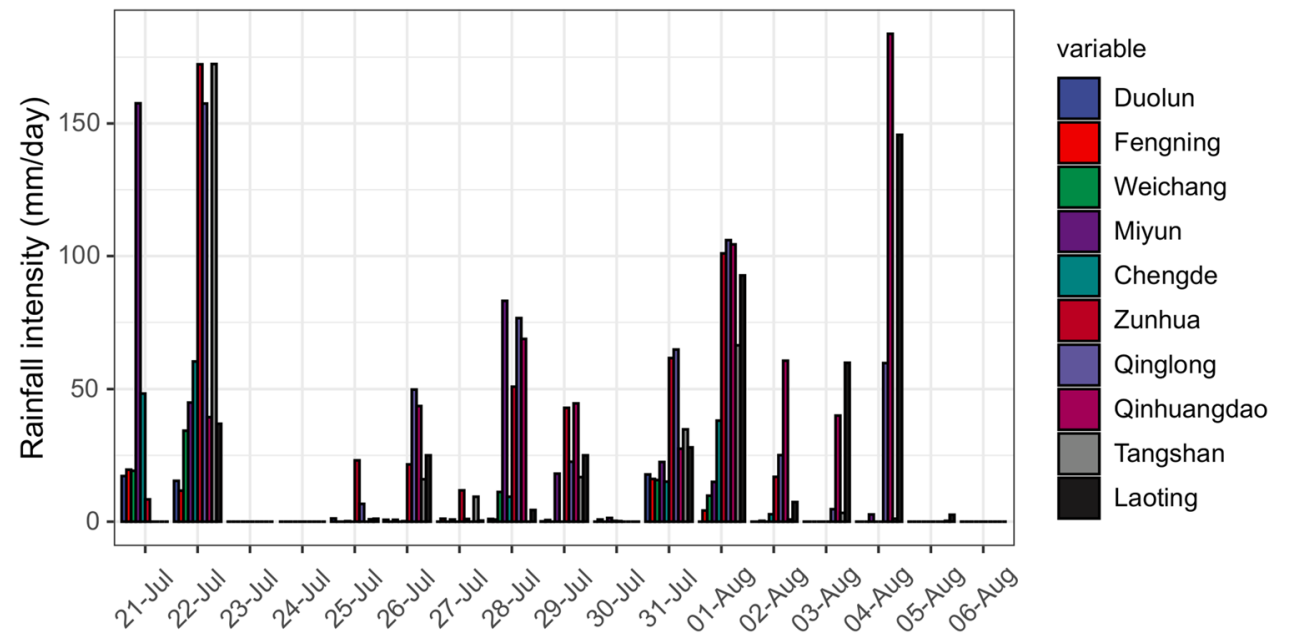

\section{Flood impact/risk assessment}

Due to the lack of data to define flood vulnerability and derive flood damage functions/curves, we combine flood modelling results with land use data to quantify the accumulative inundation areas against water depth for different land use types to indicate flood risk. The information can be further integrated with damage functions/curves to estimate flood loss when such data become available. The GPWv4 population distribution data (CIESIN 2018) are overlaid with the inundation maps to estimate the number of people affected by a flood and specify the potential hazard level. For large-scale flood impact analysis, the definition reported by Kang et al. (2006) is adopted, which classifies the hazard level to people according to flood depth as "low risk" $(0.3-1 \mathrm{~m})$, "moderate risk" (1-1.5 m), "high risk" (1.5-2 m) and "extremely high risk" (>2 m).

\section{Calibration of HiPIMS for application in LRB}

To calibrate HiPIMS for flood modelling in LRB, we consider the flood event caused by Typhoon Saola and Damrey in 2012. The Typhoon brought heavy rainfall (Fig. 4) to LRB from late July to the beginning of August 2012, leading to severe flooding in the downstream areas. The event caused 32 deaths and 12.3 billion RMB of economic losses in Hebei Province, which was one of the most severe flood disasters in LRB (Yang and Yang 2013).

The $90 \mathrm{~m}$ MERIT DEM is used to discretise the computational domain covering the whole LRB, resulting in 7.08 million valid cells for numerical calculations. Since the whole river basin is considered, the computational domain is only hydrologically linked to the outside through a tidal river mouth. The Luanhe River enters the Bohai Sea through a river mouth exposed to weak tides. The average tidal height $h_{t}$ ranges between $1-1.5 \mathrm{~m}$ (Gao and Shanming 1981) and the average slope of the river mouth area is about $S=1 / 2378$, which may be used to estimate the backwater extent as $0.7 h_{t} / S=1664-2497 \mathrm{~m}$. This suggests that the tidal boundary does not pose any significant influence on the flooding processes in the basin. Therefore, the measured rainfall as shown in Fig. 4 is used to drive the flood simulation and a free outflow boundary is imposed in the whole domain. The simulation lasts for 16 days, starting at 0:00 on 21 st July and ending at 0:00 on 6th August 2012.

To obtain the necessary data to validate the flood simulation results, the flood footprints of the region in 2012 are extracted from satellite data, including Landsat 7 (US Geological Survey 2019) and the Moderate Resolution Imaging Spectroradiometer (MODIS) (Didan et al. 2015). Nine Landsat 7 images acquired during the flooding period are processed using a data-driven Random Forest model to extract all of the water surfaces, including rivers, reservoirs/lakes and ponding areas (refer to Chen et al. (2020) for detailed implementation). However, certain inherent limitations of the Landsat 7 data may lead to underestimation of the actual water surface extent and thus flood footprints (Chen et al. 2020). Therefore, the vegetation response captured by the MODIS images is also used to identify the flood footprints by detecting the changes to the Enhanced Vegetation Index (EVI) (refer to Chen et al. (2019) for detailed implementation). The final footprints of the 2012 flood are then produced by combining the Landsat 7 water surface extent and detected vegetation response area.

One of the key model parameters in HiPIMS is the Manning $n$, which may be generally set according to land use types using textbook values (Chow 1988). However, for the built-up area, due to the use of a relatively coarse computational grid $(90 \mathrm{~m})$, it is necessary to calibrate the Manning $n$ for this land use type to account for the blockage effects created by the dense buildings and other engineering structures 
Table 5 Model parameters for the application of HiPIMS in LRB

\begin{tabular}{lllll}
\hline Parameters & $\begin{array}{l}\text { Manning coeffi- } \\
\text { cient } n\left(\mathrm{sm}^{-1 / 3}\right)\end{array}$ & $\begin{array}{l}\text { Hydraulic conductiv- } \\
\text { ity } K\left(1.0 \times 10^{-7} \mathrm{~m} / \mathrm{s}\right)\end{array}$ & $\begin{array}{l}\text { Capillary head } \psi \\
\left(1.0 \times 10^{-2} \mathrm{~m}\right)\end{array}$ & $\begin{array}{l}\text { Effective soil } \\
\text { water content } \\
\theta_{e}(-)\end{array}$ \\
\hline Land use & & & & \\
Cropland & 0.035 & 9.44 & 9.07 & 0.434 \\
Forest & 0.1 & 1.93 & 8.0 & 0.309 \\
Grassland with livestock & 0.035 & 2.08 & 6.89 & 0.401 \\
Water & 0.04 & 0.0 & 0.0 & 0.0 \\
Built-up & 0.15 & 0.0 & 0.0 & 0.0 \\
Unused land & 0.03 & 2.1 & 4.0 & 0.423 \\
\hline
\end{tabular}

that cannot be resolved by such a coarse-resolution grid. The range of Manning $n$ values for calibration is set to be $[0.1,0.15,0.2]$. Another set of model parameters is related to infiltration, which is determined by the underlying soil property but highly influenced by different land use types in real-world applications (Thompson et al. 2010; Liu et al. 2012; Wang et al. 2013; Rogger et al. 2017; de Almeida et al. 2018). The main soil types in LRB are loam, sandy loam, clay loam and sandy clay loam, and their infiltration properties are similar (Nachtergaele et al., 2009). The infiltration parameters for the LRB flood simulation are initially set for these soil types using textbook values as found in Chow (1988) and further calibrated for different land use types. Notably, LRB is typically a dry catchment throughout most of the time in a year and no significant rainfall was recorded before the flood event in 2012. Therefore, the initial soil water content for the simulation is assumed to be equal to the residual water content (i.e., $\theta_{\mathrm{ie}}=0.0$ ), and the effective soil water content $\theta_{e}$ is considered for model calibration. After neglecting infiltration for the "water" and "built-up" land use types, a Sobol sequence method (Sobol' 2001) is used to create the calibration samples of infiltration parameters for the remaining land use types including cropland, forest, grassland with livestock and unused land. Combined with the calibration samples of Manning $n$ for the built-up area, a total of 7800 groups of parameters are created and used for model calibration. The final values of the model parameters used in the simulation are summarised in Table 5 .

To quantitively compare the predicted and observed flood extents, the remotely sensed flood extent is resampled to $90 \mathrm{~m}$ resolution, i.e. the grid resolution adopted in the simulation. The overlap ratios are then calculated as follows:

$$
\begin{aligned}
O_{\mathbf{P R}} & =\mathrm{CNZ}(\mathbf{P R} \odot \mathbf{R S}) / \mathrm{CNZ}(\mathbf{P R}) \text { and } O_{\mathbf{R S}} \\
& =\mathrm{CNZ}(\mathbf{P R} \odot \mathbf{R S}) / \mathrm{CNZ}(\mathbf{R S})
\end{aligned}
$$

where $O(0 \leq O \leq 1)$ is the overlap ratio with $O=0$ indicating no overlap and $O=1$ representing a perfect match; $\mathbf{P R}$ is a Boolean matrix of the numerical results and a cell with water depth larger than $0.3 \mathrm{~m}$ is defined to be inundated; $\mathbf{R S}$ is a Boolean matrix of the remote sensing data with 0 for dry and 1 for inundated pixels; PR $\odot \mathbf{R S}$ is the Hadamard product to calculate the overlap matrix; CNZ counts the non-zero values in the corresponding matrices.

The flood extent reproduced by HiPIMS for the 2012 event with the calibrated parameters is presented in Fig. 5, comparing with the observed extent extracted from the satellite data. The overlap ratios are respectively $O_{\mathbf{P R}}=0.75$ and $O_{\mathrm{RS}}=0.71$, i.e., more than $70 \%$ of the observed inundated area is predicted to be flooded by HiPIMS. The modelling results are considered to be satisfactory for such a large-scale and relatively long simulation and the modelling approach is therefore deemed to be sufficient for the following flood simulations to support risk assessment in the LRB.

\section{Results}

The 29 flood scenarios introduced previously are simulated to produce results to investigate and discuss the flood risk in LRB under different development strategies and climate change. Driven by 100-year design rainfall, the baseline simulation for comparison is based on the 2015 land use, and the resulting basin-wise inundation map is presented in Fig. 6, showing significant inundation of the floodplains along the rivers.

\section{The impact of land use change on flooding}

Figure 7 shows the simulation results of the 100-year floods in terms of accumulative inundated areas against flood depth for each of the considered land use types for the baseline and the four projected land use scenarios. The cumulative curves represent the increment of the flooded area (vertical axis) against the increase of the flood depth (horizontal axis). The total flooded area for each of the land use types is returned and the curve becomes horizontal after the maximum water depth is reached, i.e. after all of the flooded area has been taken into account. The total flooded areas for the baseline, "Trend", "Expansion", 


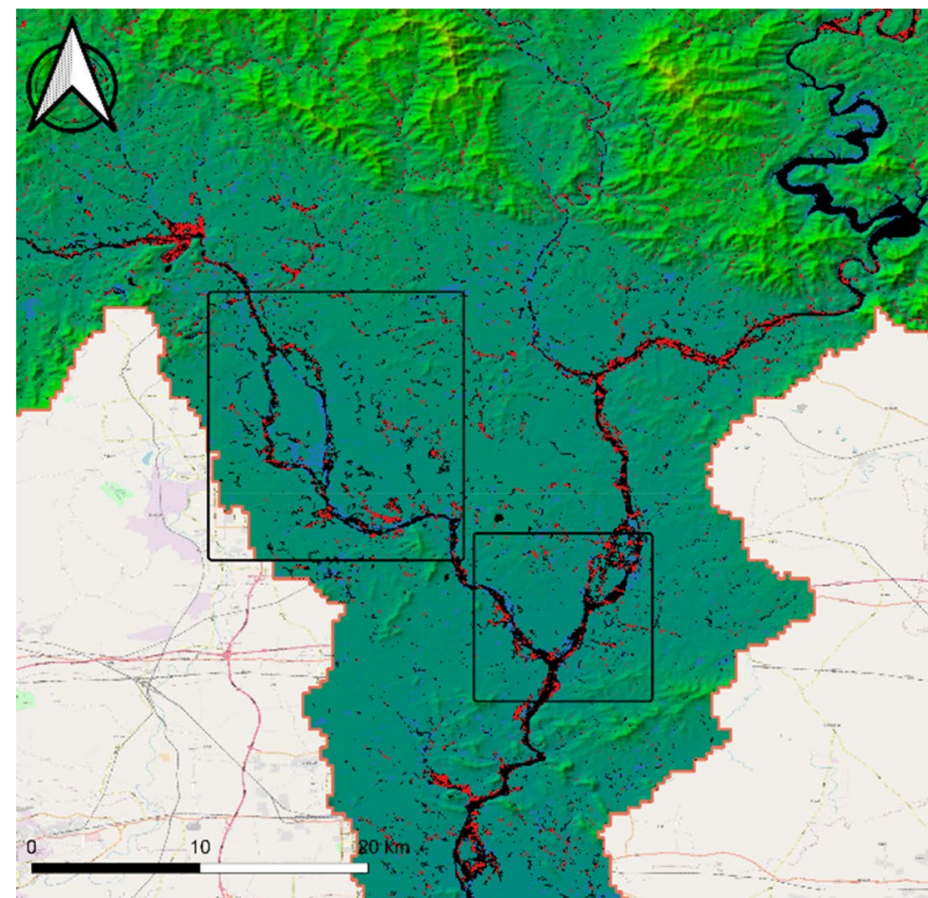

Model prediction
Remote sensing
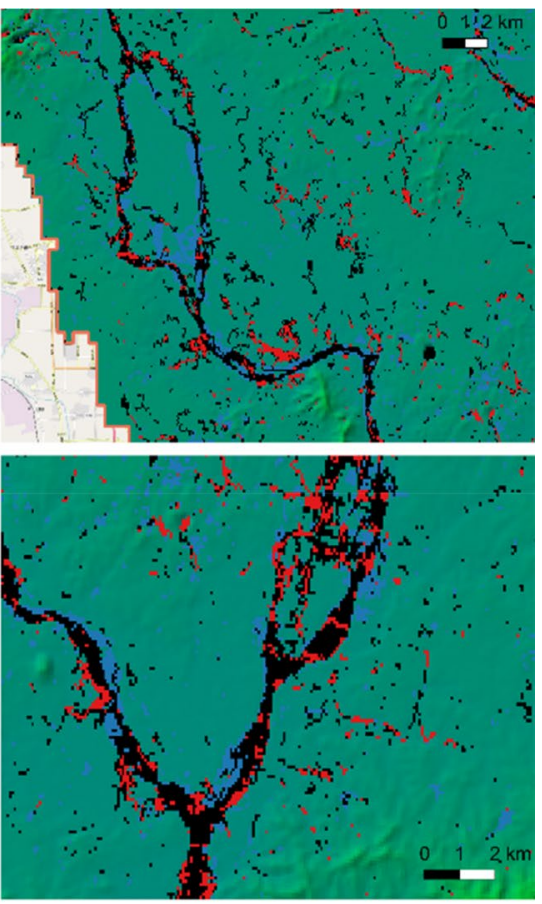

Overlap

Fig. 5 Comparison between the predicted and observed flood extents in the 2012 flood event: the zoomed-in areas located at downstream of Panjiakou reservoir (left); Qianan city (upper right); and Lulong county (lower right)

Fig. 6 The inundation map from the baseline simulation: inundation is marked in blue

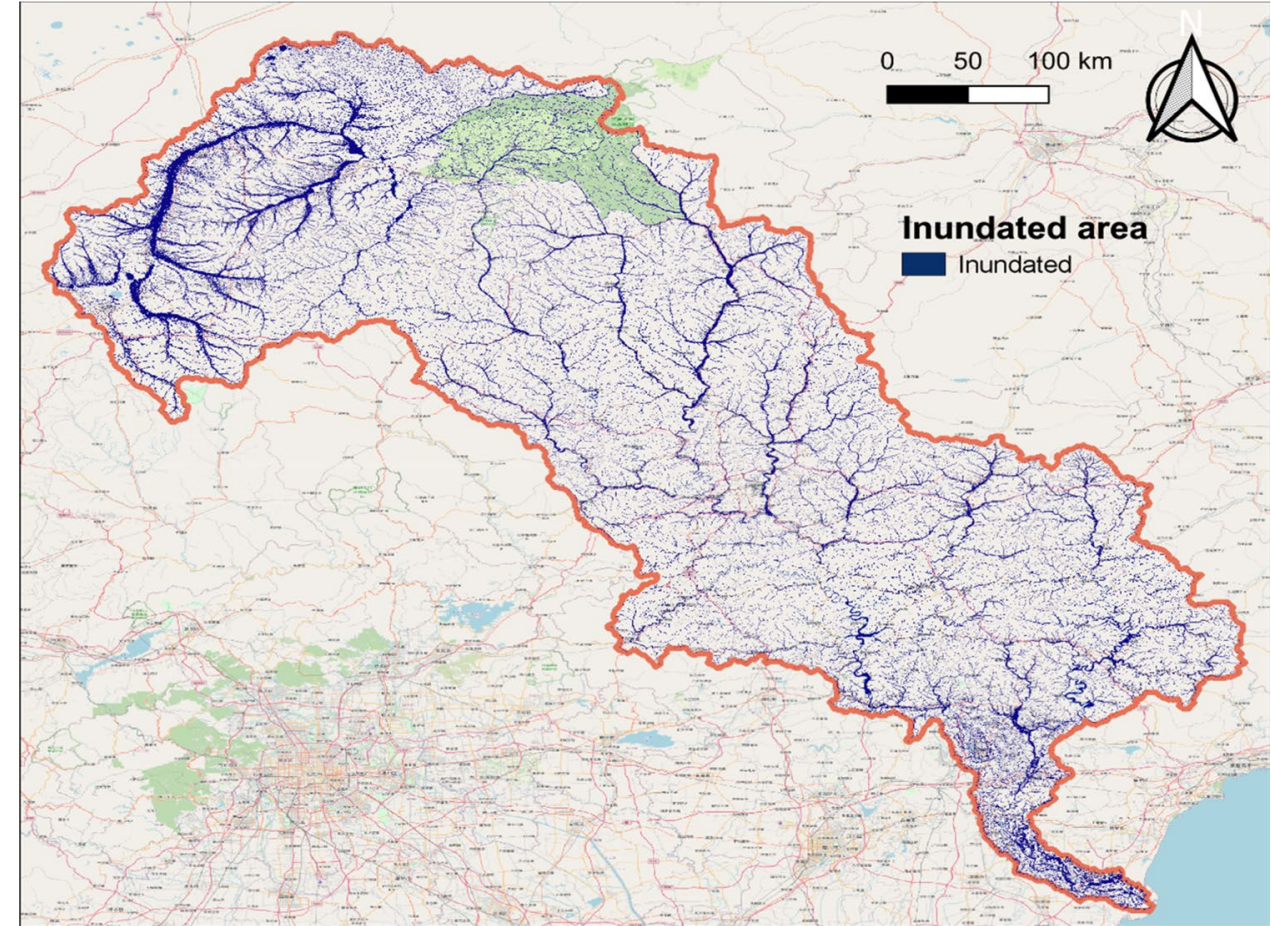

"Sustainability" and "Conservation" simulations are calculated to be $7110,7205(+1.3 \%), 7173(+0.9 \%), 7174$ $(+0.9 \%)$ and $7184(+1.0 \%) \mathrm{km}^{2}$, respectively, where the values in the brackets indicate the percentage of the increment compared to baseline result. Clearly, the total flooded areas predicted for the different scenarios do not 

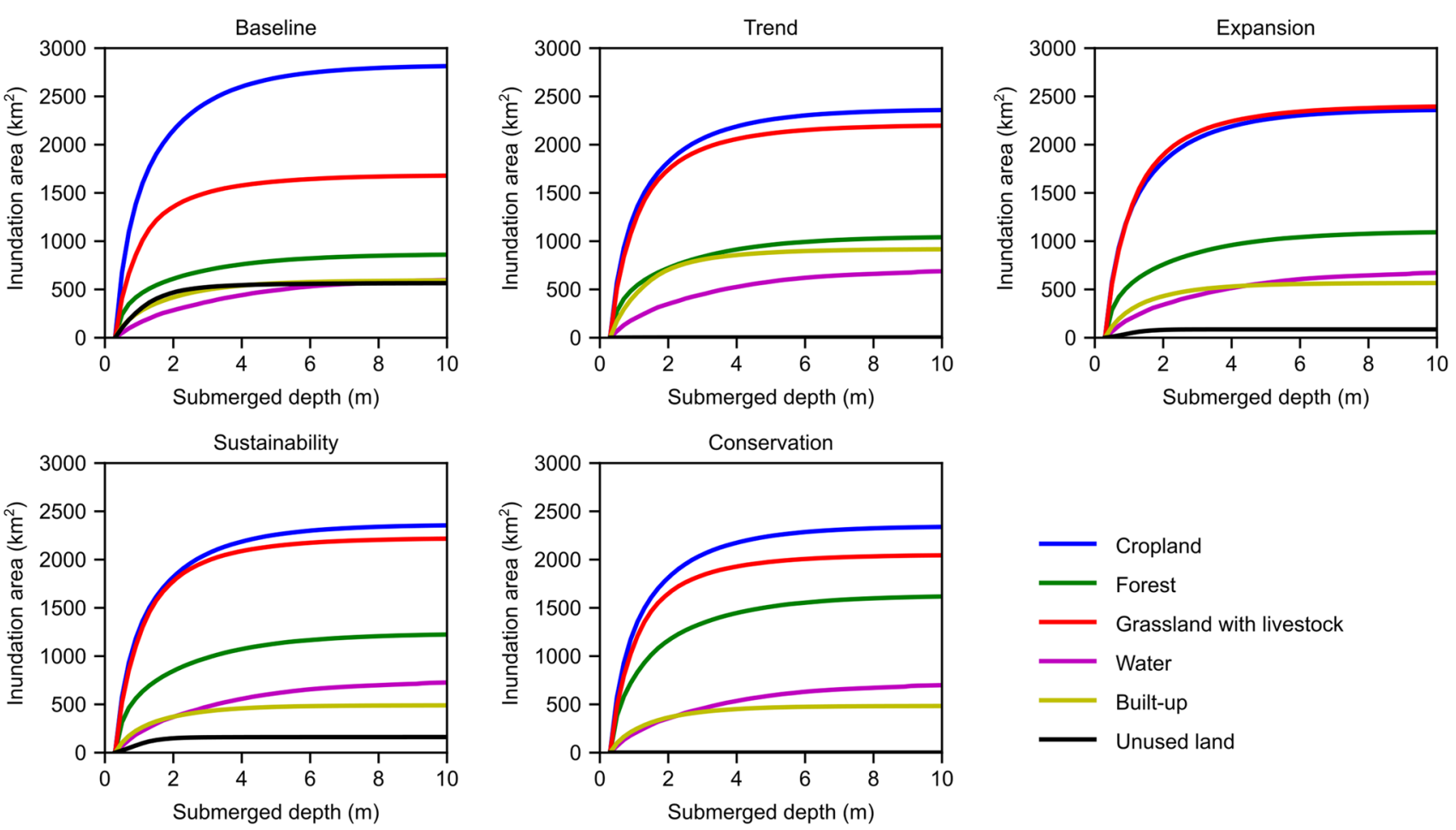

Fig. 7 Accumulative inundated areas against water depth under the baseline and the other four scenarios without considering climate change impacts

change much. This is because the inundation area is controlled mainly by the topography of the domain rather than the land use for an extreme rainfall event as considered herein. However, the distribution of the inundated land use types changes significantly across different scenarios. In the baseline scenario, whilst occupying a smaller area than forest and grassland with livestock (refer to Table 3), cropland is the most inundated type of land use. The reason is that croplands are mainly located in floodplains and relatively low-lying areas. The final inundated areas for water bodies, built-up areas, and unused land are similar.

Under the "Trend" land use/development scenario, rapid urbanisation causes expansion of the urban area (Table 3). This leads to a significant increase in the inundation of the built-up area. Similarly, the increased inundation of grassland with livestock is due to the expansion of this land use type. Although its total area increases, the inundated area of cropland decreases. This reduction may reflect the relocation of croplands to higher grounds because of rapid urbanisation at the lower levels. Whilst the forest area decreases, the inundated area remains largely unchanged compared to the baseline. The reduction of the unused area leads to the inundation of this type of land use becomes almost zero.
The "Expansion" scenario follows the global pattern of development, but since China has been the fastest developing country globally in the last 40 years, the rate of development under the "Trend" scenario is more aggressive than "Expansion". Therefore, compared with the flood simulation results for the "Trend" scenario, the built-up area in "Expansion" is smaller, and so is the corresponding inundated area. The inundated areas of all other land use types show little change, except that the inundated area of the grassland now becomes slightly larger than that of cropland. The "Expansion" scenario predicts slightly more "unused land" which is reflected in the inundation result.

For "Sustainability" and "Conservation", it is noticeable that the predicted inundation of the built-up areas decreases in comparison with the baseline simulation, although the total built-up areas slightly increase for both of these development/land use scenarios. While the total areas of forest in both scenarios do not show a significant change from the baseline, the inundated areas both increase significantly, reflecting the redistribution of land use types to support sustainable development. 

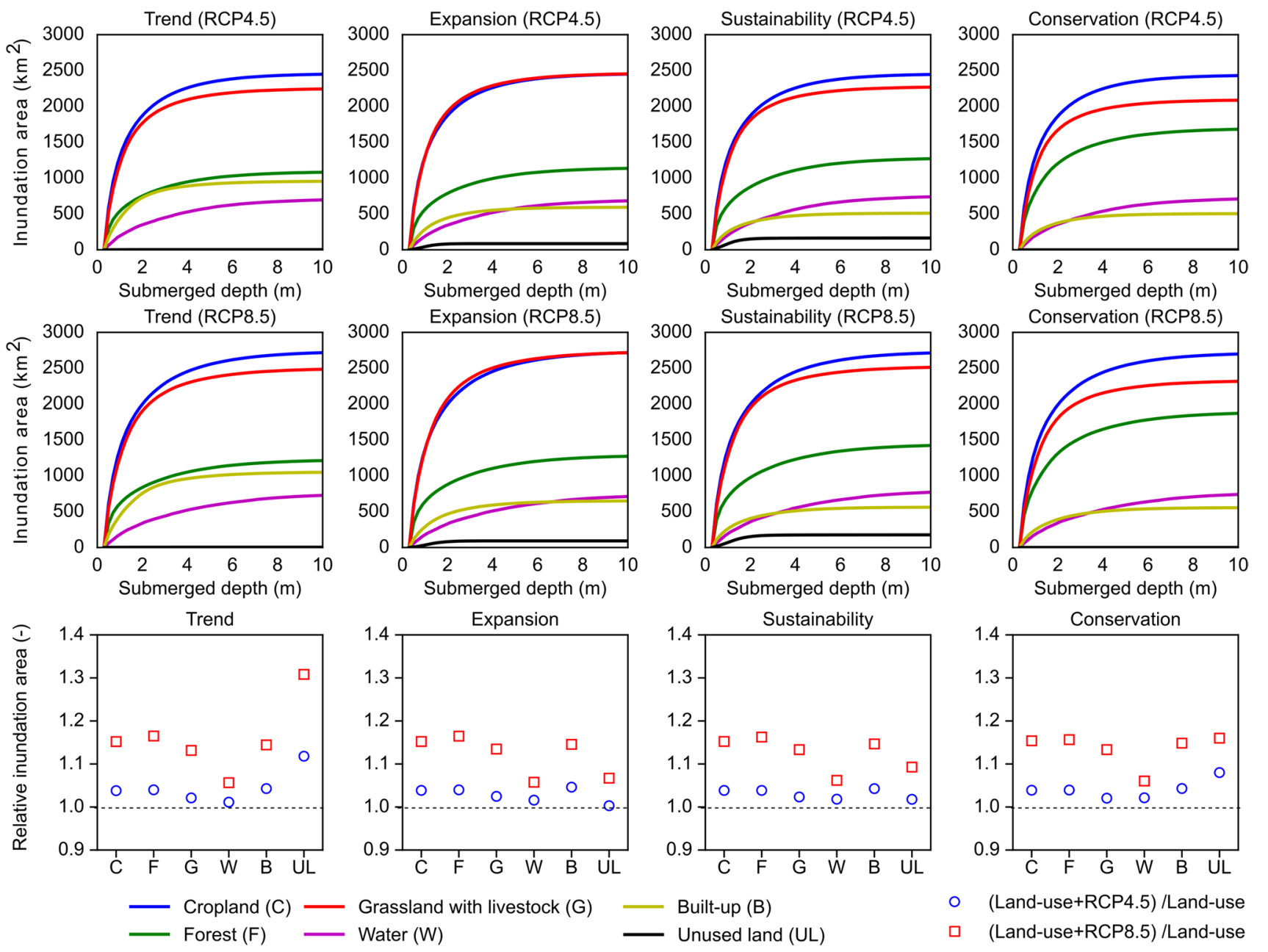

Fig. 8 Accumulative inundated areas against water depth for the four future flood scenarios, after considering climate change impacts (through RCP4.5 and RCP8.5 climate scenarios). The top two panels show the inundated areas predicted for each of the six key land use

types under the RCP4.5 and RCP8.5 climate scenarios, respectively. The bottom panel shows the corresponding ratios between the inundated areas with and without considering climate change

Fig. 9 The inundated areas of the six land use types predicted by different flood simulations

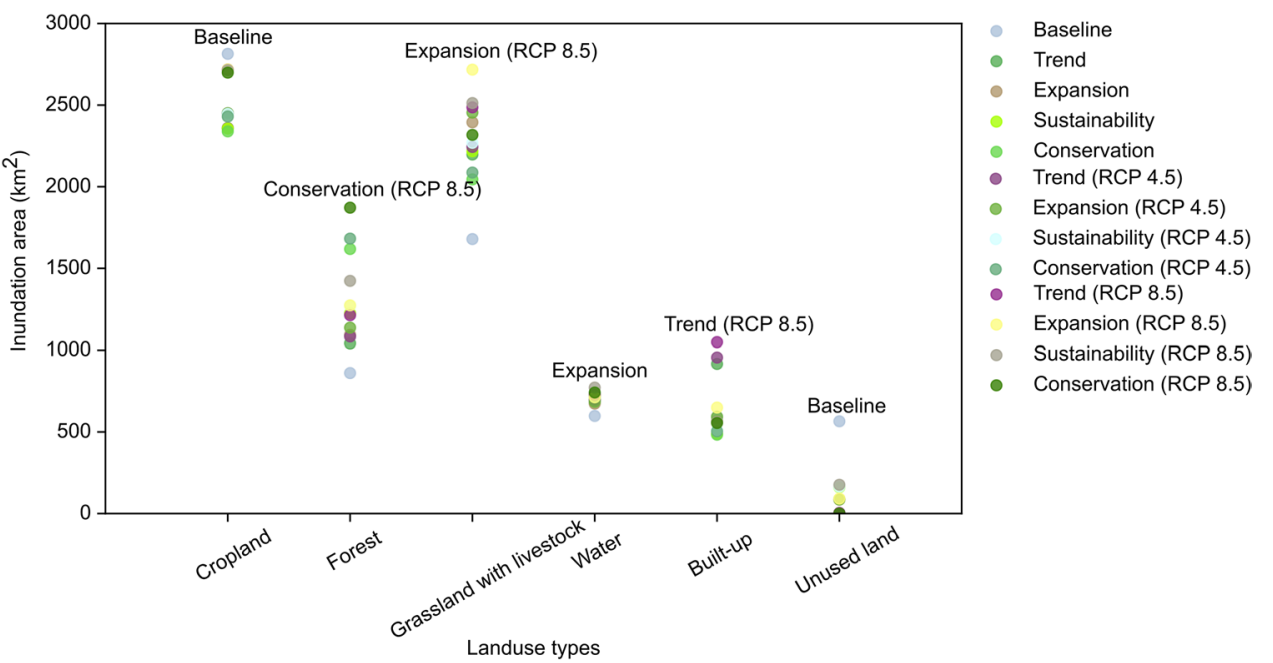


Table 6 Affected population (AP) (per 100,000 people) predicted on the four future land use scenarios with and without considering climate change, in comparison with the baseline simulation, and the corresponding RCs calculated using Eq. (7)

\begin{tabular}{|c|c|c|c|c|c|c|c|c|}
\hline \multirow[t]{2}{*}{ Affected level } & \multicolumn{2}{|c|}{ Low risk } & \multicolumn{2}{|c|}{ Moderate risk } & \multicolumn{2}{|c|}{ High risk } & \multicolumn{2}{|c|}{$\begin{array}{l}\text { Extremely high } \\
\text { risk }\end{array}$} \\
\hline & $\mathrm{AP}$ & $\mathrm{RC}$ & AP & $\mathrm{RC}$ & $\mathrm{AP}$ & $\mathrm{RC}$ & $\mathrm{AP}$ & $\mathrm{RC}$ \\
\hline \multicolumn{9}{|l|}{ Land use scenario } \\
\hline Baseline & 6505 & & 1943 & & 1283 & & 4290 & \\
\hline Trend & 6580 & 1.15 & 1992 & 2.54 & 1304 & 1.67 & 4367 & 1.79 \\
\hline Expansion & 6605 & 1.53 & 1982 & 1.98 & 1285 & 0.19 & 4323 & 0.77 \\
\hline Sustainability & 6605 & 1.53 & 1978 & 1.80 & 1294 & 0.83 & 4309 & 0.44 \\
\hline Conservation & 6602 & 1.50 & 1994 & 2.63 & 1304 & 1.65 & 4304 & 0.32 \\
\hline Trend (RCP4.5) & 6770 & 4.07 & 2028 & 4.38 & 1370 & 6.76 & 4678 & 9.05 \\
\hline Expansion (RCP4.5) & 6787 & 4.33 & 2024 & 4.15 & 1344 & 4.77 & 4642 & 8.21 \\
\hline Sustainability (RCP4.5) & 6788 & 4.35 & 2024 & 4.19 & 1342 & 4.56 & 4634 & 8.02 \\
\hline Conservation (RCP4.5) & 6781 & 4.24 & 2044 & 5.19 & 1351 & 5.30 & 4630 & 7.93 \\
\hline Trend (RCP8.5) & 7109 & 9.28 & 2154 & 10.85 & 1452 & 13.20 & 5603 & 30.61 \\
\hline Expansion (RCP8.5) & 7127 & 9.56 & 2154 & 10.88 & 1436 & 11.93 & 5557 & 29.53 \\
\hline Sustainability (RCP8.5) & 7131 & 9.63 & 2149 & 10.62 & 1440 & 12.22 & 5544 & 29.23 \\
\hline Conservation (RCP8.5) & 7121 & 9.47 & 2169 & 11.61 & 1453 & 13.21 & 5538 & 29.08 \\
\hline
\end{tabular}

\section{Impact of climate change on flooding}

Driven by the uplifted 100-year design rainfall, eight further flood simulations (Table 4) are run to consider climate change impact based on both RCP4.5 and RCP8.5 climate scenarios, and the simulation results are illustrated in Fig. 8. Whilst the distribution of inundation across different types of land use remains largely unchanged, both RCP4.5 and RCP8.5 climate scenarios cause an increase in the inundated areas across all land use types, with the RCP8.5 scenario having a greater impact. These results reflect that both of the climate scenarios predict an increase in precipitation across the basin. These simulation results demonstrate that climate change may lead to more areas being flooded and subsequently an increase in the flood risk in LRB in 2030.

Figure 9 compares the inundated areas predicted for the six key land use types in the 13 flood simulations (the baseline simulation and the 3 simulations (i.e. with and without considering the two climate change scenarios) on each of the four future land use projections). The baseline simulation predicts the maximum inundation of unused land because this land use type is projected to decrease dramatically to almost zero in all four development scenarios. However, it should be noted that the baseline simulation also returns the maximum inundated area for cropland, although the area of cropland increases in all four land use change scenarios. This apparent contradiction reflects the spatial redistribution of cropland across the basin to higher areas to make space for urban and industrial activities as the land use changes. The simulations under the RCP8.5 climate scenario predict the maximum inundated areas for all other land use types as RCP8.5 projects increased rainfall across the basin in the future.

\section{Flood impact on population}

The inundated areas are mainly distributed along rivers and adjacent floodplains where most of the population and socioeconomic activities are located. The exposure of the population to flooding can be spatially identified by overlaying the predicted inundation maps with the population distribution dataset GPWv4. Since there is no projected population distribution data in 2030, the 2015 GPWv4 dataset is used in all of the following population exposure analyses. Assuming population distribution will remain unchanged (thus representing a conservative estimate), we explore how land use and climate changes influence the exposure of the population to flooding. The flood hazard level to people can be classified based on the predicted flood depths ("Flood impact/risk assessment"). To quantitatively compare the results with the baseline simulation, the relative change to the at-risk population is calculated as:

$\mathrm{RC}=\left(\mathrm{Pop}_{s}-\mathrm{Pop}_{B}\right) / \mathrm{Pop}_{B} \times 100 \%$

where $\mathrm{Pop}_{s}$ and $\mathrm{Pop}_{B}$ are respectively the affected population estimated for the future flood scenarios and the baseline simulation. The results are summarised in Table 6, showing the affected population (AP) per 100,000 people at different hazard levels for all of the 12 future 


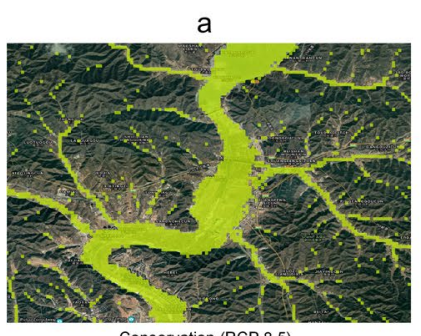

Conservation (RCP 8.5)

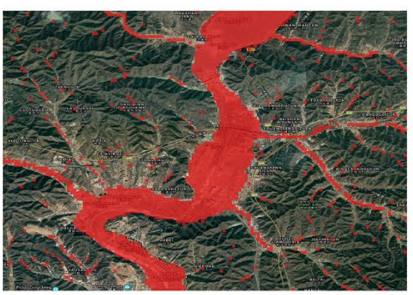

Trend (RCP 8.5)

0

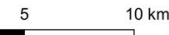

$10 \mathrm{~km}$

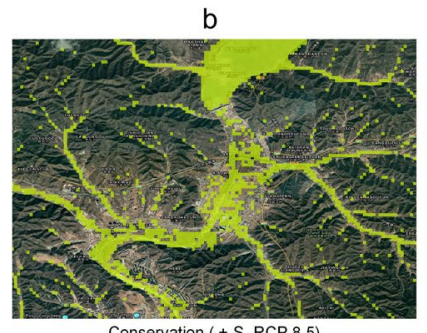

Conservation (+ S, RCP 8.5)

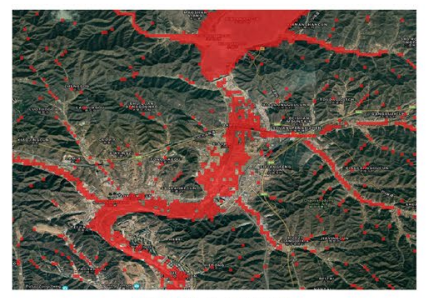

Trend (+ S, RCP 8.5)

Inundation extent: Conservation $\square>0.3$

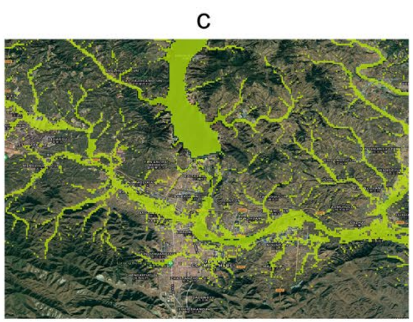

Conservation (RCP 8.5)

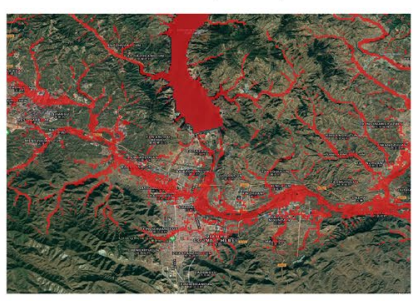

Trend (RCP 8.5)

Inundation extent: Trend

D $>0.3$
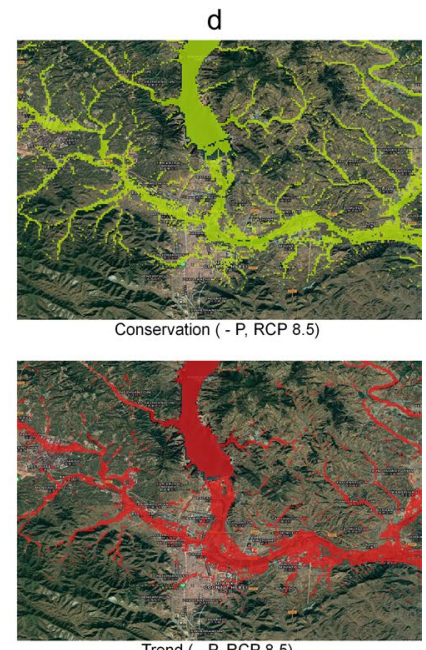

Trend (-P, RCP 8.5)

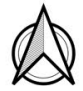

Fig. 10 Flood extents (zoom-in views to show the flooded areas adjacent to the reservoirs) predicted for the "Conservation" and "Trend" land use scenarios considering infrastructure construction: a without

scenarios and the relative change in comparison with the baseline simulation.

The results show that, across all of the scenarios, large proportion of the population is exposed to low $(7,000$ per 100,000 papulation on average) and extremely high $(5,000$ per 100,000$)$ flood risk, with smaller proportion of people having moderate or high risk (c. 2,000 and 1,000 per 100,000 population, respectively). Without climate change, the number of people exposed to flooding does not undergo substantial change under all the four future land use scenarios, with the largest RC calculated to be smaller than $2.7 \%$. Including climate change shows substantially increased flood risk to people. Under the worst RCP8.5 climate scenario, the number of people exposed to "extremely high risk" increases by c. $30 \%$ compared to the baseline.

The distribution of affected population at different hazard levels across the four land use scenarios does not show clear patterns, but the "Trend" development strategy will lead to the maximum number of people exposed to extremely high risk no matter whether climate change is considered or not. Conversely, the "Conservation" development is predicted to be the most effective at reducing the number of people subject to extremely high risk from flooding. The positive RC values show that all four development strategies will increase flood risk to people, especially under climate change conditions. This may be due to the increase of built-up areas in the low-lying areas that are more vulnerable to flooding.
Shuangfengsi Reservoir; b with Shuangfengsi Reservoir; c with Panjiakou and Daheiting Reservoirs; d without Panjiakou and Daheiting Reservoirs

\section{Potential impact of the construction of key infrastructure on flooding}

LRB provides important water resources for the downstream cities and the Beijing-Tianjin-Hebei region, and several large reservoirs have been constructed (Panjiakou, Daheiting) or are under construction (Shuangfengsi). Large reservoirs may significantly influence downstream flood risk. Therefore, further simulations (Table 3) are conducted to investigate the impact of Panjiakou and Shuangfengsi reservoirs on flood risk.

Taking the "Conservation" and "Trend" land use scenarios as examples, Fig. 10 presents the zoomed-in maps to show the impact of the reservoirs on the local inundation extents. The results shown in Fig. 10a and b indicate that including Shuangfengsi Reservoir in the simulation evidently reduces the predicted flood extent downstream, potentially providing an effective measure to mitigate the downstream flood risk. Similarly, the Pandjiakou and Daheiting Reservoirs also impact the downstream flood risk, and the simulations without including the reservoirs predict more severe flooding and greater flood extents downstream (Fig. 10c and d). However, due to the large size of the basin, the impact of these reservoirs on overall inundation extent across the basin is limited for all of the simulated scenarios (the total flooded areas when removing/including Panjiakou/ Shuangfengsi reservoirs under "Trend" development strategy with RCP8.5 climate scenario are calculated to be 8172 and $8163 \mathrm{~km}^{2}$, respectively). 
Table 7 Affected population (AP) (per 100,000 people) predicted on the future land use and climate scenarios also considering the impact of key infrastructure construction

\begin{tabular}{|c|c|c|c|c|c|c|c|c|}
\hline \multirow[t]{2}{*}{ Affected level } & \multicolumn{2}{|c|}{ Low risk } & \multicolumn{2}{|c|}{ Moderate risk } & \multicolumn{2}{|c|}{ High risk } & \multicolumn{2}{|c|}{ Extremely high risk } \\
\hline & AP & RCI & $\mathrm{AP}$ & RCI & AP & RCI & AP & RCI \\
\hline \multicolumn{9}{|l|}{ Land use scenario } \\
\hline Trend (- P, RCP4.5) & 6715 & -0.81 & 2030 & 0.10 & 1354 & -1.11 & 5213 & 11.42 \\
\hline Expansion (- P, RCP4.5) & 6734 & -0.79 & 2021 & -0.14 & 1327 & -1.29 & 5170 & 11.36 \\
\hline Sustainability (- P, RCP4.5) & 6733 & -0.81 & 2025 & 0.05 & 1321 & -1.53 & 5159 & 11.31 \\
\hline Conservation (- P, RCP4.5) & 6725 & -0.83 & 2048 & 0.18 & 1333 & -1.35 & 5148 & 11.18 \\
\hline Trend (- P, RCP8.5) & 7039 & -0.98 & 2121 & -1.54 & 1466 & 0.92 & 6202 & 10.69 \\
\hline Expansion (-P, RCP8.5) & 7062 & -0.91 & 2125 & -1.38 & 1449 & 0.88 & 6150 & 10.67 \\
\hline Sustainability (- P, RCP8.5) & 7064 & -0.94 & 2120 & -1.38 & 1455 & 1.04 & 6134 & 10.65 \\
\hline Conservation (- P, RCP8.5) & 7050 & -0.99 & 2146 & -1.02 & 1464 & 0.79 & 6118 & 10.48 \\
\hline Trend (+S, RCP4.5) & 6833 & 0.93 & 2039 & 0.52 & 1358 & -0.86 & 4161 & -11.06 \\
\hline Expansion (+S, RCP4.5) & 6848 & 0.90 & 2039 & 0.77 & 1335 & -0.72 & 4132 & -10.99 \\
\hline Sustainability (+S, RCP4.5) & 6851 & 0.93 & 2036 & 0.56 & 1336 & -0.44 & 4127 & -10.94 \\
\hline Conservation $(+\mathrm{S}, \mathrm{RCP} 4.5)$ & 6845 & 0.95 & 2053 & 0.43 & 1345 & -0.43 & 4128 & -10.85 \\
\hline Trend (+S, RCP8.5) & 7189 & 1.13 & 2197 & 2.00 & 1454 & 0.11 & 4985 & -11.03 \\
\hline Expansion (+S, RCP8.5) & 7203 & 1.07 & 2195 & 1.86 & 1439 & 0.19 & 4944 & -11.03 \\
\hline Sustainability (+S, RCP8.5) & 7209 & 1.09 & 2190 & 1.89 & 1440 & 0.04 & 4934 & -11.01 \\
\hline Conservation $(+\mathrm{S}, \mathrm{RCP} 8.5)$ & 7197 & 1.07 & 2203 & 1.58 & 1458 & 0.39 & 4937 & -10.84 \\
\hline
\end{tabular}

However, downstream of these reservoirs are urbanised areas with high population densities, and so the impact of the reservoirs on the safety of the downstream population may affect the basin-wise statistics. To assess this, the relative change to the at-risk population related to infrastructure construction (RCI) is calculated against the previous flood simulation results as:

$\mathrm{RCI}=\left(\mathrm{Pop}_{s, I}-\mathrm{Pop}_{s}\right) / \mathrm{Pop}_{s} \times 100 \%$

where Pop $_{s, I}$ is the population affected by flooding after including/removing reservoirs, as appropriate. The numbers of affected population from different simulations and the values of RCI are summarised in Table 7 . The results clearly indicate that these large reservoirs reduce the risk to people downstream, and the values of RCI are calculated to be $\pm 10 \%$ for the extremely high-risk population in all of the simulated scenarios.

\section{Discussion and conclusion}

Driven by the city-wise 100-year design rainfall, a total of 28 future flood scenarios are simulated in this work using a high-performance flood inundation model to better understand the basin-scale flood risk in the whole LRB. The scenarios vary by different land use, climate change and key infrastructure construction conditions. The four future land use scenarios are projected to 2030 to reflect different development strategies and used to explore the relationships between flood risk, policy-driven development and realisation of Sustainable Development Goals.

\section{Flood risk under different development and climate scenarios}

The flood simulation results show that different land use changes do not significantly influence the total inundated area across the basin for the extreme 100-year rainfall under consideration. This is because flood inundation is distributed mainly according to hydrological processes and the basin topography rather than land use under the extreme rainfall conditions. However, the inundated areas of individual land use types vary significantly in different scenarios due to relocation and expansion/reduction of different types of land use. For example, whilst the area of forested land is projected to decrease in the "Trend", "Expansion" and "Sustainability" land use scenarios, the inundation of this land use type is predicted to increase in all four scenarios, potentially due to the redistribution of forest areas into flood-prone areas. Commonly being located on flat lands close to water resources (rivers) and occupying a large area, the agricultural land use types including cropland and grassland with livestock are most exposed to flooding and have the largest inundated areas in all of the simulations, including the baseline simulation. The "Trend" scenario predicts rapid urban expansion, including development in flood-prone zones. This gives rise to a significant increase in the inundation of 
built-up land, potentially putting a much larger population at risk of flooding and creating much higher economic losses.

Climate change impacts are taken into account by deriving city-wise uplift factors to adjust the design rainfall under the two IPCC recommended future climate scenarios, RCP4.5 and RCP8.5. Climate change will increase future rainfall intensity in LRB, leading to higher flood peaks and the prediction of increased total inundated areas across the basin. However, the distribution of the inundated areas between different land use types does not show significant change. The RCP8.5 climate scenario predicts a greater uplift in rainfall than RCP4.5 and subsequently much greater inundated areas across the basin and for most of the land use types. These predictions are consistent for all four land use scenarios (see Fig. 9).

Based on the 2015 global population distribution data from GPWv4, the number of people affected by flooding to different hazard levels is estimated. The population at risk of flooding does not show much change between the simulations under different land use scenarios. This insensitivity to the development scenarios may be related to several potential reasons. A large portion of the population is located in the low-lying areas close to rivers, which are always more vulnerable to flooding. Whilst the built-up area may expand to different extents in different development scenarios, the newly developed areas will increasingly be located at higher grounds and hence are less exposed to flooding. The existing urbanised zones will continue to develop but normally will not be relocated and replaced by another land use type. The population distribution is based on the 2015 data and has not been projected to take account of potential changes in total population by 2030 , which represents a limitation of this work.

LRB contains several large reservoirs, and their impact on downstream flood risk is also explored. Through simulations with and without including reservoirs, it is found that, whilst the reservoirs can mitigate flood risk in the downstream areas close to their locations, their impact on the basin-wide flood inundation is limited. However, due to the existence of major cities downstream, the large reservoirs can effectively reduce the number of people at extremely high risk of flooding, and the relative change of the extremely high-risk population can reach $10 \%$ for all of the simulated scenarios.

\section{Interactions between Sustainable Development Goals}

All of the four future development strategies considered for the LRB are projected to induce significant land use change, which will influence future flood risk and affect SDG achievement in LRB. As Northern China's most forested river basin, development strategies under the "Sustainability" and "Conservation" scenarios will further increase the forest area. This directly links to SDG 15 on terrestrial ecosystem conservation and management, including forests. The increase in cropland and grassland areas due to the increase in livestock breeding will exert different impacts on achieving SDG 2, which aims at ending hunger, achieving food security, improving nutrition and promoting sustainable agriculture. Increased waters, e.g., through the construction of reservoirs, water transport systems and irrigation systems, will help achieve SDG 6, including its targets to address water accessibility, improve water quality and water-use efficiency, and protect water-related ecosystems, including mountain forests and wetlands, rivers, aquifers and lakes/ reservoirs. Achieving SDG 6 can further generate synergies with SDG 15 and SDG 2 via enhanced ecosystem services, particularly related to the provision and regulation services and improved irrigation systems. Moreover, as a vital water source for Tianjin Municipality, the realisation of SDG 6 in LRB will contribute to achieving SDGs in Tianjin as water is an essential resource supporting all aspects of life and social-economic development. The expansion of builtup land under the "Trend" and "Expansion" development strategies will substantially increase the areas of human settlement and cities, contributing to economic growth through infrastructure development and industrialisation. This will directly contribute to SDG 11 on sustainable cities and communities such as Target 11.1 on safe and affordable housing. However, rapid urbanisation may lead to the generation of pollutants, effluents and solid wastes, which could damage public health (SDG 3), water resources (SDG 6) and related ecosystems (Goal 15). Detailed analysis of the synergies and trade-offs between SDGs under different development strategies in LRB can be found in Zhou et al. (2021).

Effective management of flood risk, or disaster risk reduction (DRR) in general, is directly or indirectly embedded in the SDG framework and is a critical aspect for consideration when evaluating the impacts of national and regional development strategies on SDGs. Based on the preceding results and analysis, whilst different development strategies may not lead to substantial changes in the total flooded area across the basin, the inundated areas of different land use types can be significantly changed and shifted. It is therefore necessary to analyse in more detail the impact of flooding on different land use types to better understand the complex relationships between flood risk and socio-economic development and how the synergies and trade-offs between the SGDs are affected. For example, the "Trend" development strategy is predicted to see rapid socio-economic development and substantial expansion of built-up areas. This may positively contribute to SDG 8 in terms of promoting economic growth and providing full and productive employment and decent work for all, and is therefore related to SDG 1 (No Poverty). However, this will inevitably increase flood inundation of built-up areas and pose higher flood risk to 
people, properties and businesses, which will in turn create trade-offs for achieving other SDGs.

Climate change may increase the frequency and intensity of extreme rainfall, and hence flood risk. This in turn can substantially increase the number of people exposed to high and extremely high risk from flooding (Tables 6 and 7). This may directly affect the realisation of SDG 1 (e.g., Target 1.5 on building resilience to disasters), SDG 11 (e.g., Target 11.5 on reducing the adverse effects of disasters), SDG 13 (e.g., Target 13.1 on strengthening resilience and capacity to climate-related hazards and disasters), among others. Meanwhile, different development strategies may influence or intensify climate change to different levels.

Construction of key infrastructure, e.g., dams and reservoirs, may help better regulate water resources and protect people from flooding damage, but it may also exert negative impacts on the environment. All these will further complicate the issues and create challenges in evaluating the relationship between development strategies and SDG attainment, as well as the linkages between SDGs.

\section{Limitations of this study}

This work presents a new framework to systematically analyse basin-wide flood risk in connection to different development scenarios in LRB. The study is subject to several limitations that need to be resolved in future work. First, the resolutions of different spatial datasets are not consistent. For example, both the land use and the GPWv4 population distribution data are at $1000 \mathrm{~m}$ resolution, which is resampled to $90 \mathrm{~m}$ to match the resolution of the adopted DEM to support flood modelling and the following analysis. This will inevitably introduce uncertainties to the analysis and results. Secondly, GPWv4 does not provide future projections, and the population distribution data available for the baseline year of 2015 is directly used in all of the analyses to identify the at-risk population, assuming there is no change to the population distribution from 2015 to 2030 . The land use change, especially the expansion of the built-up area, may encourage redistribution and migration of population, and such a rough assumption may affect the accuracy of at-risk population statistics. Therefore, the conclusions from this analysis may be conservative and should be used with care.

Furthermore, the adopted global climate dataset (NEXGDDP) has 1950-2005 as the retrospective period. But in the current study, 2015 is adopted as the baseline year to produce future development/land use scenarios. To obtain the climate uplift factors against 2015, simple linear interpolation is implemented by assuming climate change affects design rainfall linearly across time. The assumption may be rough, and the climate projections and uplift factors should be adjusted in the future if local climate data are available.
Moreover, the initial soil conditions for all of the scenario simulations are assumed to be the same as those adopted for the 2012 event. Although the soil conditions of the basin are not expected to change significantly, the initial soil water content will be highly influenced by hydrological/weather conditions before the flood event occurs and also land use. But since LRB is a dry catchment and major precipitation occurs in a short wet period of a year, it seems to be reasonable to assign infiltration parameters according to the soil conditions following a dry season, as done in this work. In the future, it is worth further investigating the effect of varying initial soil water content conditions on the flood simulation and risk analysis results.

Finally, due to the lack of relevant socio-economic data, the potential flood losses cannot be quantified. But the simulation results are presented as accumulated inundated areas against inundation depth, which can be directly coupled with socio-economic data and vulnerability curves to estimate flood losses when such information becomes available.

\section{Conclusion}

From the simulation and analysis results, the following conclusions are drawn:

- Whilst the basin-wide inundated areas are predicted to be similar under different land use change scenarios for the extreme 100-year rainfall as considered in this work, the inundated areas of individual land use types may vary significantly, indicating different exposure to flood risk.

- The number of people at high risk of flooding is closely linked to the distribution of the built-up areas, which commonly accommodate dense population and are located in low-lying areas and floodplains that are more vulnerable to flooding. All four land use change scenarios project expanded built-up area, leading to increased flood risk to the people.

- Climate change, especially the RCP8.5 climate scenario, may lead to more frequent and intense rainfall, subsequently causing an increase in the total inundated areas as well as the number of people at high and extremely high risk of flooding.

- Large dams and reservoirs can substantially reduce inundation in the downstream areas close to the dam sites but only have a limited impact on the total inundated areas across the basin. Dams and reservoirs may provide critical protection to the downstream population and substantially reduce the number of people exposed to extremely high risk. However, large dams and reservoirs may pose an adverse impact on the environment and increase the risk of catastrophic dam-break floods. 
It is evident from the modelling and analysis results that flood risk at LRB is closely related to different development strategies, which will affect the realisation of SDGs. It is essential to investigate and understand the inter-dependent relationships between basin development strategies, flood risk and realisation of SDGs to inform the development of a suitable policy to ensure the sustainable future of LRB. This will help minimise the trade-offs and maximise the synergies between SDGs. The proposed basin-scale flood risk assessment framework provides an important tool for this purpose. Based on a physically based high-performance hydrodynamic flood model and open data, the framework can be readily applied to other river basins, especially those in developing countries where access to high-quality data from government agencies is limited.

Acknowledgements This research is funded by the Natural Environment Research Council (NERC) of the UK Research and Innovation (UKRI) through the Towards a Sustainable Earth (TaSE) programme (NE/S012427/1).

Open Access This article is licensed under a Creative Commons Attribution 4.0 International License, which permits use, sharing, adaptation, distribution and reproduction in any medium or format, as long as you give appropriate credit to the original author(s) and the source, provide a link to the Creative Commons licence, and indicate if changes were made. The images or other third party material in this article are included in the article's Creative Commons licence, unless indicated otherwise in a credit line to the material. If material is not included in the article's Creative Commons licence and your intended use is not permitted by statutory regulation or exceeds the permitted use, you will need to obtain permission directly from the copyright holder. To view a copy of this licence, visit http://creativecommons.org/licenses/by/4.0/.

\section{References}

Akter T, Quevauviller P, Eisenreich SJ, Vaes G (2018) Impacts of climate and land use changes on flood risk management for the Schijn River, Belgium. Environ Sci Policy 89:163-175. https:// doi.org/10.1016/j.envsci.2018.07.002

Arnell NW, Gosling SN (2016) The impacts of climate change on river flood risk at the global scale. Clim Change 134:387-401. https:// doi.org/10.1007/s10584-014-1084-5

Baldassarre GD, Sivapalan M, Rusca M et al (2019) Sociohydrology: scientific challenges in addressing the Sustainable Development Goals. Water Resour Res 55:6327-6355. https://doi.org/10.1029/ 2018WR023901

Bevacqua E, Maraun D, Vousdoukas MI et al (2019) Higher probability of compound flooding from precipitation and storm surge in Europe under anthropogenic climate change. Sci Adv 5:eaaw5531. https://doi.org/10.1126/sciadv.aaw5531

Bi W, Weng B, Yuan Z et al (2018) Evolution Characteristics of Surface Water Quality Due to Climate Change andLUCC under Scenario Simulations: A Case Study in the Luanhe River Basin. IJERPH 15:1724. https://doi.org/10.3390/ijerph15081724

Bosher L, Chmutina K (2017) Disaster risk reduction for the built environment. John Wiley and Sons Ltd., Chichester

Bouwer LM, Bubeck P, Aerts JCJH (2010) Changes in future flood risk due to climate and development in a Dutch polder area. Glob
Environ Chang 20:463-471. https://doi.org/10.1016/j.gloenvcha. 2010.04.002

Center for International Earth Science Information Network-CIESINColumbia University (2018) Gridded Population of the World, version 4 (GPWv4): population density, revision 11. NASA Socioeconomic Data and Applications Center (SEDAC), Palisades

Chang H-K, Tan Y-C, Lai J-S et al (2013) Improvement of a drainage system for flood management with assessment of the potential effects of climate change. Hydrol Sci J 58:1581-1597. https://doi. org/10.1080/02626667.2013.836276

Chen H, Liang Q, Liang Z et al (2019) Remote-sensing disturbance detection index to identify spatio-temporal varying flood impact on crop production. Agric for Meteorol 269-270:180-191. https:// doi.org/10.1016/j.agrformet.2019.02.002

Chen H, Liang Q, Liang Z et al (2020) Extraction of connected river networks from multi-temporal remote sensing imagery using a path tracking technique. Remote Sens Environ 246:111868. https://doi.org/10.1016/j.rse.2020.111868

Chow VT (1988) Applied hydrology. Applied hydrology. McGrawHill, New York

CRED, UNDRR (2020) The human cost of disasters: an overview of the last 20 years 2000-2019. CRED, UNDRR, Geneva

de Almeida WS, Panachuki E, de Oliveira PTS et al (2018) Effect of soil tillage and vegetal cover on soil water infiltration. Soil Tillage Res 175:130-138. https://doi.org/10.1016/j.still.2017.07.009

Didan K, Munoz AB, Solano R, Huete A (2015) MODIS vegetation index user's guide (MOD13 series). University of Arizona: Vegetation Index and Phenology Lab

Gao S, Shanming G (1981) Facies and sedimentary model of the Luan riverdelta. Acta Geogr Sin 36:303-314. https://doi.org/10.11821/ xb198103006

Gilroy KL, McCuen RH (2012) A nonstationary flood frequency analysis method to adjust for future climate change and urbanization. J Hydrol 414-415:40-48. https://doi.org/10.1016/j.jhydrol.2011. 10.009

Han Z (1999) Flood analysis of "94.7" Rainstorm in Luanhe River Basin. Hebei Water Resour 2:28-29

Heber Green W, Ampt GA (1911) Studies on soil phyics. J Agric Sci 4:1-24. https://doi.org/10.1017/S0021859600001441

Hirabayashi Y, Mahendran R, Koirala S et al (2013) Global flood risk under climate change. Nat Clim Chang 3:816-821. https://doi.org/ 10.1038/nclimate1911

IPCC (2014) Climate change 2014: synthesis report. Contribution of working groups I, II and III to the fifth assessment report of the intergovernmental panel on climate change. IPCC 27:408

Jiang H, Wang Z, Ye A et al (2019) Hydrological characteristic-based methodology for dividing flood seasons: an empirical analysis from China. Environ Earth Sci 78:399. https://doi.org/10.1007/ s12665-019-8392-z

Kang X, Wu S, Dai E et al (2006) Pre-assessment of loss and impact of large-scale flood disaster. Chin Sci Bull 3:155-164

Keifer CJ, Chu HH (1957) Synthetic storm pattern for drainage design. J Hydraul Div 83:1332-1341

Li Y, Huang S-L, Domagalski J (2018) Temporal and spatial distributions of water and sediment yield in the Luanhe River Basin. China Coas 84:149-162. https://doi.org/10.2112/SI84-021.1

Liang Q, Smith LS (2015) A high-performance integrated hydrodynamic modelling system for urban flood simulations. J Hydroinf 17:518-533. https://doi.org/10.2166/hydro.2015.029

Liu Y (2012) An analysis of the hydrology, geology and economic situation of luanhe river basin. J Hebei Norm Univ Natl 32:2426. https://doi.org/10.16729/j.cnki.jhnun.2012.02.006

Liu Y, Fu B, Lü Y et al (2012) Hydrological responses and soil erosion potential of abandoned cropland in the Loess Plateau, China. Geomorphology 138:404-414. https://doi.org/10.1016/j. geomorph.2011.10.009 
Lizarralde G, Chmutina K, Bosher L, Dainty A (2015) Sustainability and resilience in the built environment: the challenges of establishing a turquoise agenda in the UK. Sustain Cities Soc 15:96-104. https://doi.org/10.1016/j.scs.2014.12.004

Lu R (2005) Interannual variation of North China rainfall in rainy season and SSTs in the equatorial eastern Pacific. Chin Sci Bull 50:2069-2073. https://doi.org/10.1007/BF03322803

Lugeri N, Kundzewicz ZW, Genovese E et al (2010) River flood risk and adaptation in Europe-assessment of the present status. Mitig Adapt Strateg Glob Change 15:621-639. https://doi.org/ 10.1007/s11027-009-9211-8

Miller JD, Hutchins M (2017) The impacts of urbanisation and climate change on urban flooding and urban water quality: a review of the evidence concerning the United Kingdom. J Hydrol 12:345-362. https://doi.org/10.1016/j.ejrh.2017.06.006

Nachtergaele F, van Velthuizen H, Verelst L, et al (2010) The harmonized world soil database. In: Proceedings of the 19th world congress of soil science, soil solutions for a changing world, Brisbane, Australia, 1-6 August 2010. pp 34-37

O’Neill BC, Kriegler E, Riahi K et al (2014) A new scenario framework for climate change research: the concept of shared socioeconomic pathways. Clim Change 122:387-400. https://doi.org/ 10.1007/s10584-013-0905-2

Rogger M, Agnoletti M, Alaoui A et al (2017) Land use change impacts on floods at the catchment scale: challenges and opportunities for future research. Water Resour Res 53:5209-5219. https://doi.org/10.1002/2017WR020723

Schuster ZT, Potter KW, Liebl DS (2012) Assessing the effects of climate change on precipitation and flood damage in Wisconsin. J Hydrol Eng 17:888-894. https://doi.org/10.1061/(ASCE)HE. 1943-5584.0000513

Scott M, White I, Kuhlicke C et al (2013) Living with flood risk/ The more we know, the more we know we don't know: Reflections on a decade of planning, flood risk management and false precision/Searching for resilience or building social capacities for flood risks?/Participatory floodplain management: Lessons from Bangladesh/Planning and retrofitting for floods: Insights from Australia/Neighbourhood design considerations in flood risk management/Flood risk management: challenges to the effective implementation of a paradigm shift. Plan Theory Pract 14:103-140. https://doi.org/10.1080/14649357.2012.761904

Shao X, Liu J, Liu Y (2001) Research on hazard inducing environment which caused drought-flood disasters in Hebei province. Territ Nat Resour Study 23(2):1-3 (in Chinese)

Sheng F, Xiuling C (2004) Influence of atmospheric precipitation on soil leaching and desalinization in semi-humid region. In: 13th International Soil Conservation Organization Conference, Conserving Soil and Water for Society: Sharing Solutions-Brisbane

Sobol' IM (2001) Global sensitivity indices for nonlinear mathematical models and their Monte Carlo estimates. Math Comput Simul 55:271-280. https://doi.org/10.1016/S0378-4754(00) 00270-6

Te Linde AH, Bubeck P, Dekkers JEC et al (2011) Future flood risk estimates along the river Rhine. Nat Hazard 11:459-473. https:// doi.org/10.5194/nhess-11-459-2011

Thompson SE, Harman CJ, Heine P, Katul GG (2010) Vegetationinfiltration relationships across climatic and soil type gradients. J Geophys Res Biogeosci. https://doi.org/10.1029/2009JG001134
Thrasher B, Nemani R (2015) Nasa earth exchange global daily downscaled projections (nex-gddp). NASA, Washington, DC, USA

UN (United Nations) (2015) Transforming our world: the 2030 agenda for sustainable development. UN (United Nations), New York

UNISDR (United Nations International Strategy for Disaster Reduction United Nations) (2015) Sendai framework for disaster risk reduction 2015-2030. UNISDR, Geneva

US Geological Survey (2019) Landsat 7 (L7) data users handbook. US Geological Survey, New York

van Asselen S, Verburg PH (2013) Land cover change or land-use intensification: simulating land system change with a global-scale land change model. Glob Change Biol 19:3648-3667. https://doi. org/10.1111/gcb.12331

Wang S, Fu B, Gao G et al (2013) Responses of soil moisture in different land cover types to rainfall events in a re-vegetation catchment area of the Loess Plateau, China. CATENA 101:122-128. https:// doi.org/10.1016/j.catena.2012.10.006

Wheater H, Evans E (2009) Land use, water management and future flood risk. Land Use Policy 26:S251-S264. https://doi.org/10. 1016/j.landusepol.2009.08.019

Wu Y, Zhang X, Fu Y et al (2020) Response of vegetation to changes in temperature and precipitation at a semi-arid area of northern China based on multi-statistical methods. Forests 11:340. https:// doi.org/10.3390/f11030340

Xia X, Liang Q, Ming X (2019) A full-scale fluvial flood modelling framework based on a high-performance integrated hydrodynamic modelling system (HiPIMS). Adv Water Resour 132:103392. https://doi.org/10.1016/j.advwatres.2019.103392

Xing Y, Liang Q, Wang G et al (2019) City-scale hydrodynamic modelling of urban flash floods: the issues of scale and resolution. Nat Hazards 96:473-496. https://doi.org/10.1007/s11069-018-3553-z

Xu Y-P, Zhang X, Tian Y (2012) Impact of climate change on 24-h design rainfall depth estimation in Qiantang River Basin, East China. Hydrol Process 26:4067-4077. https://doi.org/10.1002/ hyp. 9210

Xu J, Renaud FG, Barrett B (2021) Modelling land system evolution and dynamics of terrestrial carbon stocks in the Luanhe River Basin, China: a scenario analysis of trade-offs and synergies between Sustainable Development Goals. Sustain Sci. https:// doi.org/10.1007/s11625-021-01004-y

Yang M, Yang X (2013) Analysis on characteristics of "12.8 flood" occurred in Luanhe River Basin and its flood control operation. Water Resour Hydropower Eng 44(6): 112-116 (in Chinese)

Zhao J, Liang Q (2021) New Godunov-type finite volume schemes for hydrodynamic modelling of overland flow and surface water flooding [Manuscript submitted for publication]. Adv Water Resour

Zhou X, Moinuddin M, Renaud FG et al (2021) Analysis of the synergies and trade-offs between Sustainable Development Goals at the river basin scale: an empirical study for China's Luanhe River Basin from an SDG interlinkage perspective. Sustain Sci (in press)

Publisher's Note Springer Nature remains neutral with regard to jurisdictional claims in published maps and institutional affiliations. 